\title{
Water and magmas: insights about the water solution mechanisms in alkali silicate melts from infrared, Raman, and ${ }^{29} \mathrm{Si}$ solid- state NMR spectroscopies
}

\author{
Charles Le Losq*, Bjorn O. Mysen and George D. Cody
}

\begin{abstract}
Degassing of water during the ascent of hydrous magma in a volcanic edifice produces dramatic changes in the magma density and viscosity. This can profoundly affect the dynamics of volcanic eruptions. The water exsolution history, in turn, is driven by the water solubility and solution mechanisms in the silicate melt. Previous studies pointed to dissolved water in silicate glasses and melts existing as molecules $\left(\mathrm{H}_{2} \mathrm{O}_{\text {mol }}\right.$ species $)$ and hydroxyl groups, $\mathrm{OH}$. These latter $\mathrm{OH}$ groups commonly are considered bonded to $\mathrm{Si}^{4+}$ but may form other bonds, such as with alkali or alkaline-earth cations, for instance. Those forms of bonding influence the structure of hydrous melts in different ways and, therefore, their properties. As a result, exsolution of water from magmas may have different eruptive consequences depending on the initial bonding mechanisms of the dissolved water. However, despite their importance, the solution mechanisms of water in silicate melts are not clear. In particular, how chemical composition of melts affects water solubility and solution mechanism is not well understood. In the present experimental study, components of such information are reported via determination of how water interacts with the cationic network of alkali ( $\mathrm{Li}, \mathrm{Na}$, and $\mathrm{K}$ ) silicate quenched melts. Results from ${ }^{29} \mathrm{Si}$ single-pulse magic-angle spinning nuclear magnetic resonance $\left({ }^{29} \mathrm{Si}\right.$ SP MAS NMR), infrared, and Raman spectroscopies show that decreasing the ionic radius of alkali metal cation in silicate melts results in decreasing fraction of water dissolved as $\mathrm{OH}$ groups. The nature of $\mathrm{OH}$ bonding also changes as the alkali ionic radius changes. Therefore, as the speciation and bonding of water controls the degree of polymerization of melts, water will have different effects on the transport properties of silicate melts depending on their chemical composition. This conclusion, in turn, may affect volcanic phenomena related to the viscous relaxation of hydrous magmas, such as for instance the fragmentation process that occurs during explosive eruptions.
\end{abstract}

Keywords: Melt; Glass; Structure; Water bonding; Water speciation; NMR spectroscopy; Raman spectroscopy; Viscosity; Magma; Fragmentation

\section{Background}

Water is typically the major volatile component in magmas and can reach concentrations up to $\sim 6-7$ wt. \% in silicic magma chambers (e.g., see Blake 1984; Clemens 1984). When magmas migrate from their source up towards the Earth surface, water exsolution can result in large (up to several orders of magnitude) increases in magma viscosity because of the strong effect of water on the viscosity of

\footnotetext{
* Correspondence: clelosq@carnegiescience.edu

Geophysical Laboratory, Carnegie Institution of Washington, 5251 Broad Branch Road NW, Washington, DC 20015, USA
}

silicate melts (Leonteva 1940; Saucier 1952; Friedman et al. 1963; Shaw 1963; Dingwell et al. 1996; Richet et al. 1996). Water exsolution is also accompanied by the formation of vapor bubbles that participate in decreasing the bulk density of the magma, reinforcing, in this way, the buoyant force that pushes the magma out of the Earth crust. In silica-poor magmas with viscosities lower than $10^{6} \mathrm{~Pa} \mathrm{~s}$ at eruptive temperature, such as with basalts, gas bubbles can coalesce and escape from the magma (Thomas et al. 1994; Gardner et al. 1996). This situation usually results in gentle (lava flows) to slightly explosive

\section{勿}


(lava fountain, strombolian explosion) eruptions. In contrast, for silica-rich compositions, the magma viscosity can be considerably higher than $10^{6} \mathrm{~Pa} \mathrm{~s}$ at eruptive temperature, so that bubbles are trapped in the melts (Thomas et al. 1994; Gardner et al. 1996). Exsolution of water from such magmatic liquids often results in foaming. In such case, brittle fragmentation of the magmatic foam can occur, for example, when the elongation strain rate of the foam ascending in the conduit exceeds its viscous relaxation time (Papale 1999). This situation leads to explosive eruptions.

The effects of water on magma properties, together with their possible consequences as described above, result from how water affects the disordered tetrahedral silicate network of melts. A simple and commonly proposed solution mechanism of water in such melts involves the presence of $\mathrm{H}_{2} \mathrm{O}$ molecules $\left(\mathrm{H}_{2} \mathrm{O}_{\text {mol }}\right)$, which can react with the oxygens $\mathrm{O}$ of the silicate network to form $\mathrm{OH}$ groups:

$$
\mathrm{H}_{2} \mathrm{O}_{\text {mol (melt) }}+\mathrm{O}_{(\text {melt })}<=>2 \mathrm{OH}_{(\text {melt })}
$$

The solution mechanism illustrated in Eq. (1) is documented by numerous nuclear magnetic resonance (NMR) and infrared (IR) spectroscopic studies (e.g., Scholtze 1960; Moulson and Roberts 1961; Bartholomew et al. 1980; Stolper 1982; Kohn et al. 1989a, b; Zotov and Keppler 1998), which also indicated that $\mathrm{OH}$ groups seem bonded predominantly to Si (see also Farnan et al. 1987; Cody et al. 2005; Mysen and Cody 2005). Therefore, in this simple model, $\mathrm{H}_{2} \mathrm{O}_{\text {mol }}$ reacts predominantly with bridging oxygens $(\mathrm{BO}$ ), breaking $\mathrm{T}-\mathrm{O}-\mathrm{T}$ bonds (with $\mathrm{T}=\mathrm{Si}, \mathrm{Al}$ ), so that Eq. (1) can be rewritten as:

$$
\mathrm{H}_{2} \mathrm{O}_{\text {mol (melt) }}+\mathrm{T}-\mathrm{O}-\mathrm{T}_{(\text {melt })}<=>2 \mathrm{~T}-\mathrm{OH}_{(\text {melt })}
$$

Equation (2) implies formation of non-bridging oxygens (NBO) when the reaction shifts to the right. However, reaction (2) does not always proceed to completion. Indeed, both $\mathrm{H}_{2} \mathrm{O}_{\text {mol }}$ and $\mathrm{OH}$ groups coexist in silicate melts, and hence glasses, in proportions defined by temperature (Nowak and Behrens 1995; Sowerby and Keppler 1999; Behrens and Yamashita 2008) and apparently water concentration (e.g., Stolper 1982).

However, Eq. (2) is just one reaction describing the reaction of $\mathrm{H}_{2} \mathrm{O}$ with the silicate network of silicate melts. Other dissolution mechanisms have been proposed, such as the formation of $\mathrm{MOH}$ bonds (with $\mathrm{M}^{+, 2+}$ a metallic ion) (Xue and Kanzaki 2004, 2006, 2008; Moretti et al. 2014) or the protonation of T-O-T bonds $\left(\mathrm{H}^{+}\right.$does not break T-O-T bonds but is attached to it; see for example Kohn et al. 1989b, 1992, 1998 and references therein). Moreover, Eq. (2) does not consider the $Q^{n}$ speciation often employed to describe the silicate structure (where $n$ denotes the number of bridging oxygen in a silicate complex, see Schramm et al. 1984). For example, water can react with different $Q^{n}$ species in sodium silicate melts depending on their initial water content and $\mathrm{Na} / \mathrm{Si}$ ratio (Zotov and Keppler 1998; Mysen and Cody 2005; Mysen 2007). In addition, it appears likely that the electronic properties of the alkali and alkaline earth metal cations will affect the reaction mechanisms of water with the silicate network (Xue and Kanzaki 2004).

To understand, quantitatively, how water interacts with the silicate structure of glasses and melts, we examined the structure of alkali $\left(\mathrm{Li}^{+}, \mathrm{Na}^{+}, \mathrm{K}^{+}\right)$tetrasilicate glasses using Raman and ${ }^{29} \mathrm{Si}$ SP MAS NMR spectroscopy. Existing infrared spectroscopic information (Le Losq et al. 2015a, b) was also used. By studying such compositionally simple systems, it is possible to isolate effects of individual components on the water solution behavior. Furthermore, the chosen glasses have anhydrous glass transition temperature, $\mathrm{Tg}$, within a $\sim 30 \mathrm{~K}$ range: the $\mathrm{Tg}$ of the sodium tetrasilicate glass is $751 \mathrm{~K}$ (Neuville 2006), that of the potassium tetrasilicate glass to $762 \mathrm{~K}$ (Neuville 1992), and that of the LS4 glass to $740 \mathrm{~K}$ (Voigt et al. 2005). They also have very similar distributions of silicate $Q^{n}$ species (e.g., Maekawa et al. 1991). Those two characteristics (comparable anhydrous $T_{g} \mathrm{~s}$ and $Q^{n}$ distributions) allow us to emphasize differences that characterize the hydrous quenched melts rather than differences related to the starting anhydrous glasses.

\section{Methods}

\section{Sample preparation}

The starting materials as well as the hydrous glasses used for this study are the same as those reported in Le Losq et al. (2015a, b). We refer readers to these references for details on sample synthesis. The chemical compositions of glass starting materials are reported in Table 1.

Table 1 Chemical composition of LS4, NS4, and KS4 anhydrous glasses

\begin{tabular}{llllll}
\hline & & $\mathrm{SiO}_{2}$ & $\mathrm{Li}_{2} \mathrm{O}$ & $\mathrm{Na}_{2} \mathrm{O}$ & $\mathrm{K}_{2} \mathrm{O}$ \\
\hline \multirow{2}{*}{$\mathrm{LS4}$} & nom. mol \% & 80.00 & 20.00 & 0.00 & 0.00 \\
& nom. wt. \% & 88.94 & 11.08 & 0.00 & 0.00 \\
& meas. wt. \% & $88.77(94)$ & $11.23(75)$ & n.a. & n.a. \\
\multirow{2}{*}{ NS4 } & nom. mol \% & 80.0 & 0.00 & 20.00 & 0.00 \\
& nom. wt. \% & 79.50 & 0.00 & 20.50 & 0.00 \\
& meas. wt. \% & $80.38(36)$ & n.a. & $19.62(31)$ & n.a. \\
& nom. mol \% & 80.0 & 0.00 & 0.00 & 20.0 \\
KS4 & nom. wt. \% & 71.84 & 0.00 & 0.00 & 28.16 \\
& meas. wt. \% & 71.16 (49) & n.a. & n.a. & $28.84(28)$
\end{tabular}

nom. mol \%, nom. wt. \%, and meas. wt. \% refer respectively to the nominal compositions in mol and wt. \% and to the measured composition in wt. \%. Chemical compositions are from Le Losq et al. (2015a). Errors are given at the $1 \sigma$ confidence interval 
The ${ }^{29} \mathrm{Si}$ NMR signal from the anhydrous glasses suffers from a very long $T_{1}$ relaxation time. To reduce this $T_{1}$ relaxation time, a portion of the starting glasses was synthesized with a few hundred ppm $\mathrm{Fe}_{2} \mathrm{O}_{3}$, as previously done by Maekawa et al. (1991) to study similar alkali silicate glasses. To ensure homogeneous distribution of this small amount of iron oxide in the materials, the glass synthesis was done in two steps. The first step consisted in enriching a proportion of the starting glasses to 15 wt. $\% \mathrm{Fe}_{2} \mathrm{O}_{3}$. During the second step, the iron-rich glasses were crushed and then mixed with crushed iron-free starting materials, in order to produce iron-enrichment in the 100-1000 ppm concentration range.

Quantitative analysis of the glasses by energy-dispersive $\mathrm{x}$-ray spectrometry (EDS) was performed with a JEOL fieldemission scanning electron microscope (FE-SEM) equipped with an Oxford silicon drift detector and using a $15 \mathrm{kV}$ accelerating voltage and a $1.00 \mathrm{nA}$ current. Measurements were performed scanning 25 by 25 micron areas. The EDS results were calibrated using the following standards: pyrope for $\mathrm{O}$ and $\mathrm{Si}$, scapolite for $\mathrm{Na}, \mathrm{K} 1597 \mathrm{GI}$ for $\mathrm{K}$, and cossyrite for Fe. Calibration was based on a set of glass standards. The EDS results are within error of standards analyzed as unknowns.

The compositions of the Fe-doped glasses are essentially the same as those of the Fe-free starting materials. The iron contents are below detection limit ( 200 ppm) for Fe-doped LS4, $1500 \pm 300$ ppm for Fe-doped NS4, and $700 \pm 400 \mathrm{ppm}$ for Fe-doped KS4 (mean values and errors from $>10$ individual measurements made at different spots). These Fe-doped glasses were used only to perform the ${ }^{29} \mathrm{Si}$ NMR measurements of anhydrous endmembers. Optically, they are clear and colorless with the same Raman signal as iron-free starting glasses, indicating a homogeneous distribution of Fe in their structure. This is supported by SEM observations that show no clustering of iron at the micrometer scale. The ${ }^{29} \mathrm{Si}$ NMR data of the hydrous glasses were obtained on ironfree glasses. Indeed, in those water-bearing glasses, the ${ }^{1} \mathrm{H}$ nuclei that have a strong magnetic moment serve to aid the relaxation of ${ }^{29} \mathrm{Si}$ nuclei, as $\mathrm{Fe}$ at the \%o level does in the anhydrous glasses.

\section{Solid-state NMR spectroscopy}

Silicon-29 solid-state NMR experiments were carried out with a Chemagnetics CMX Infinity 300 solid-state NMR spectrometer. The static field strength of the magnet is $\sim 7.05 \mathrm{~T}$, and the Larmor frequency of ${ }^{29} \mathrm{Si}$ is $\sim 59 \mathrm{MHz}$ at this magnetic field. ${ }^{29} \mathrm{Si}$ spectra were referenced to tetramethylsilane (TMS), defined as $0 \mathrm{ppm}$.

Single-pulse ${ }^{29} \mathrm{Si}$ MAS spectra of each glass were obtained by spinning the samples at $11 \mathrm{kHz} .{ }^{29} \mathrm{Si}$ excitation pulse widths corresponded to $30^{\circ}$ tip angles. One thousand acquisitions separated by a $100 \mathrm{~s}$ recycling time were co- added. Proton decoupling was performed with continuous $\mathrm{RF}$ irradiation at $62.5 \mathrm{kHz}$. As indicated in the "Sample preparation" section, the anhydrous starting materials had a long ${ }^{29} \mathrm{Si}$ spin lattice $T_{1}$ relaxation time. For the KS4 glass, this long relaxation time resulted in a signal from ${ }^{29} \mathrm{Si}$ in $Q^{4}$ polymerized units much too low compared to a prediction of a mixture of $50 \% Q^{3}: 50 \% Q^{4}$ units based on glass chemical composition. Therefore, a portion of the anhydrous samples was doped with iron (see "Sample preparation" section) in order to decrease of the ${ }^{29} \mathrm{Si} T_{1}$. The resulting signal from KS4 glass was much more intense than without the iron dopant and the spectra yielding $Q^{3}-Q^{4}$ proportion near the nominal 50:50. In hydrous glasses, which were iron-free, the protons played a similar role as iron, thus reducing the ${ }^{29} \mathrm{Si}$ spin-lattice relaxation time, so that spectra are directly quantitative. More details on the ${ }^{29} \mathrm{Si}$ singlepulse NMR experiments can be found in Cody et al. (2005).

\section{Raman spectroscopy}

Raman spectra were recorded with a Jasco NRS 3100 spectrometer, equipped with holographic gratings, a single monochromator, and a $1024 \times 128$ Andor DV401-F1 CCD Peltier-cooled detector operating at $-70{ }^{\circ} \mathrm{C}$. The $490 \mathrm{~nm}$ line of a coherent solid-state laser was used for sample excitation, with a power of $\sim 44 \mathrm{~mW}$ on sample. The laser was focused on sample through a $50 \times$ Olympus lens. The groove density of the gratings was 2400 lines/ $\mathrm{mm}$, which results in an accuracy of $\pm 3 \mathrm{~cm}^{-1}$. Precision was $\pm 1 \mathrm{~cm}^{-1}$. Alignment of the Raman spectrometer was tested against the $520.7 \mathrm{~cm}^{-1}$ Raman peak of pure Si. All spectra reported in this study are unpolarized. The spectra were not corrected from temperature and excitation line effects (e.g., see Neuville et al. 2014, for further discussion about the relevance of such corrections) because thermal effects mostly affect the Raman intensity at frequency below $500 \mathrm{~cm}^{-1}$, which does not contain much information relevant to the focus of the present study, and because excitation line effects are very small and in all cases will not affect our results since we used the same laser line for recording all spectra.

The Raman spectra were fitted using Gaussian peaks. A two-step fitting procedure was employed. As both the number of peaks and the frequency range of the fitted region are large, a first fitting step was carried out by using an equal peak width for all peaks. This fit was accomplished by using the nlinfit non-linear leastsquare optimization function of Matlab. Then, in order to refine the models produced by nlinfit, the parameters and associated errors from those fits were injected in the pseudo-Newtonian algorithm described in Tarantola (2005) and used in Le Losq et al. (2014). This algorithm has the advantage of accounting of the a priori errors on the initial models (e.g., the errors on the estimations provided by the user or by nlinfit in 
our case). Errors in peak areas were calculated by propagating the peak parameter errors.

\section{Water concentration}

Water concentrations $\left[\mathrm{H}_{2} \mathrm{O}^{\mathrm{TOT}}\right]$ of hydrous glasses were determined from IR absorption spectroscopy data of the NS4 compositions (for which molar absorption coefficients are available; Yamashita et al. 2008) and an FTIRbased calibration of the relative area of the $\mathrm{OH}$ fundamental stretch Raman band for the LS4 and KS4 glasses as described by Le Losq et al. (2015a). The resulting water contents together with glass synthesis conditions are reported in the Table 2 .

The molar absorption coefficients of $\mathrm{OH}$ groups and $\mathrm{H}_{2} \mathrm{O}_{\text {mol }}$ species for LS4 glasses have been estimated by using the IR data reported in Le Losq et al. (2015b) and the data treatment reported in Le Losq et al. (2015a), which follows the protocol described in Yamashita et al. (2008). A six-order polynomial baseline was fitted on spectra to derive a baseline under the 4500 and $5200 \mathrm{~cm}^{-1}$ IR absorption peaks (see Fig. 1, top left) and subtracted from spectra. Then, areas of the 4500 (A4500) and 5200 (A5200) $\mathrm{cm}^{-1}$ IR peaks, assigned to $\mathrm{OH}$ groups and $\mathrm{H}_{2} \mathrm{O}_{\text {mol }}$ species respectively (Scholtze 1960; Moulson and Roberts 1961; Stolper 1982), have been measured (Table 2). The absorption coefficients of these two peaks ( $\varepsilon_{5200}$ and $\varepsilon_{4500}$, respectively) were calculated from the following relationship (Yamashita et al. 2008):

$$
\frac{1820 \times \mathrm{A} 5200}{d \times \rho \times\left[\mathrm{H}_{2} \mathrm{O}^{\mathrm{TOT}}\right]}=\varepsilon_{5200}-\frac{\varepsilon_{5200}}{\varepsilon_{4500}} \times\left[\frac{1820 \times \mathrm{A} 4500}{d \times \rho \times\left[\mathrm{H}_{2} \mathrm{O}^{\mathrm{TOT}}\right]}\right]
$$

with $d$, the thickness of the double-polished glass piece, and $\rho$, its density. The density of anhydrous LS4 glass was taken from Tischendorf et al. (1998). The density of hydrous glasses was then estimated by assuming a linear mixing between the molar volume of water and that of the glasses. In the water content range of the present study, such an assumption seems valid in light of the results of Yamashita et al. (2008) for sodium silicate glasses, and, on a larger dataset, with the results of Richet et al. (2000). According to results from those two studies, a partial molar volume of $12 \mathrm{~cm}^{3} \mathrm{~mol}^{-1}$ for dissolved water was chosen. Such a value may overestimate slightly the actual molar volume of water in lithium silicate glasses, as inferred from results from ${ }^{1} \mathrm{H}$ NMR spectroscopy on these same glasses (Le Losq et al. 2015a). However, a change of the partial molar volume of water of $4 \mathrm{~cm}^{3} \mathrm{~mol}^{-1}$ for instance can result in a maximum change of $4 \mathrm{~L} \mathrm{~mol}^{-1} \mathrm{~cm}^{-2}$ of the absorption coefficients. Such variations are incorporated in the reported error bars. By using Eq. (3), $\varepsilon_{5200}=56 \pm$ $8(1 \sigma) \mathrm{L} \mathrm{mol}^{-1} \mathrm{~cm}^{-2}$ and $\varepsilon_{4500}=70 \pm 7(1 \sigma) \mathrm{L} \mathrm{mol}^{-1}$ $\mathrm{cm}^{-2}$ for the LS4 glass.

Use of the IR combination peaks at 4500 and $5200 \mathrm{~cm}^{-1}$ to determine water content of glasses is only possible when those peaks are well defined. In water-bearing alkali silicate glasses, an increase of the ionic radius of alkali (decreasing their ionic field strength) produces a decrease of the $\mathrm{O}-\mathrm{O}$ distances around protons dissolved as $\mathrm{H}_{2} \mathrm{O}_{\text {mol }}$ species and $\mathrm{OH}$ groups (Le Losq et al. 2015a). This perturbs significantly the frequency and intensity of the signal assigned to $\mathrm{O}-\mathrm{H}$ stretching vibrations in IR and Raman spectra of hydrous alkali silicate glasses (Le Losq et al. 2015b). For example, in IR spectra of KS4 glasses, this signal extends to frequencies much lower than $3000 \mathrm{~cm}^{-1}$, presenting several intensity maxima near $\sim 2350, \sim 2800$, and $\sim 3600 \mathrm{~cm}^{-1}$. This extended frequency range results in a poorly defined $4500 \mathrm{~cm}^{-1}$ combination band (Le Losq et al. 2015b) so that this

Table 2 Water concentration of glasses

\begin{tabular}{|c|c|c|c|c|c|c|c|c|}
\hline \multirow[t]{2}{*}{ Glass } & \multirow[t]{2}{*}{ nom. mol \% $\mathrm{H}_{2} \mathrm{O}$} & \multirow{2}{*}{$\begin{array}{l}\text { Conditions of } \\
\text { synthesis }\end{array}$} & \multicolumn{5}{|c|}{ FTIR values } & \multirow{2}{*}{$\begin{array}{l}\text { RAMAN } \\
{\left[\mathrm{H}_{2} \mathrm{O}^{\text {TOT }}\right]}\end{array}$} \\
\hline & & & $\mathrm{A}_{4200}$ & $A_{5200}$ & {$[\mathrm{OH}]$} & {$\left[\mathrm{H}_{2} \mathrm{O}_{\mathrm{mol}}\right]$} & {$\left[\mathrm{H}_{2} \mathrm{O}^{\mathrm{TOT}}\right]$} & \\
\hline \multirow[t]{3}{*}{ LS4 } & 3.28 & $1650^{\circ} \mathrm{C}$ & $151(12)$ & $93(9)$ & $2.11(35)$ & $1.04(22)$ & 3.15 & $3.08(60)$ \\
\hline & 9.40 & $1.5 \mathrm{GPa}$ & $325(18)$ & $452(21)$ & $4.56(70)$ & $5.06(42)$ & $9.61(81)$ & $10.09(60)$ \\
\hline & 17.64 & & $447(21)$ & 1109 (33) & $6.26(94)$ & $12.42(55)$ & $18.68(1.09)$ & $18.74(60)$ \\
\hline \multirow[t]{3}{*}{ NS4 } & 3.28 & $1500^{\circ} \mathrm{C}$ & $155(12)$ & $3(2)$ & $3.85(40)$ & $0.07(3)$ & $3.92(40)$ & $3.44(67)$ \\
\hline & 9.40 & $1.5 \mathrm{GPa}$ & $301(17)$ & $86(9)$ & $7.35(63)$ & $1.89(20)$ & $9.24(66)$ & $9.46(67)$ \\
\hline & 17.64 & & $403(20)$ & $440(21)$ & $9.52(80)$ & $9.35(60)$ & $18.87(1.00)$ & $17.54(67)$ \\
\hline \multirow[t]{3}{*}{ KS4 } & 3.28 & $1550^{\circ} \mathrm{C}$ & - & - & $3.98(70)^{a}$ & $0.00(0)^{a}$ & - & $3.98(74)$ \\
\hline & 9.40 & $1.5 \mathrm{GPa}$ & - & - & $8.89(70)^{a}$ & $0.73(7)^{a}$ & - & $9.62(74)$ \\
\hline & 17.64 & & - & - & $13.65(70)^{a}$ & $2.30(24)^{a}$ & - & $15.95(74)$ \\
\hline
\end{tabular}

Nom. refers to the nominal water concentrations. $\left[\mathrm{H}_{2} \mathrm{O}_{\text {mol }}\right],[\mathrm{OH}]$, and $\left[\mathrm{H}_{2} \mathrm{O}^{\mathrm{TOT}}\right]$ concentrations are in mol \%. $\mathrm{A}_{4500}$ and $\mathrm{A}_{5200}$ are the integrated intensities of the $\mathrm{IR}$ peaks at $\sim 4500$ and $\sim 5200 \mathrm{~cm}^{-1}$ that have been used to quantify the content of $[\mathrm{OH}]$ and $\left[\mathrm{H}_{2} \mathrm{O}_{\text {mol }}\right.$ for the LS4 and NS4 glasses. FTIR and Raman values are from Le Losq et al. (2015a). Errors are given at the $1 \sigma$ confidence interval

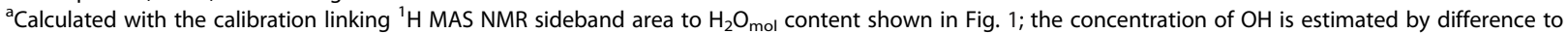
$\left[\mathrm{H}_{2} \mathrm{O}_{\text {mol }}\right]$ measured with using Raman spectroscopy 

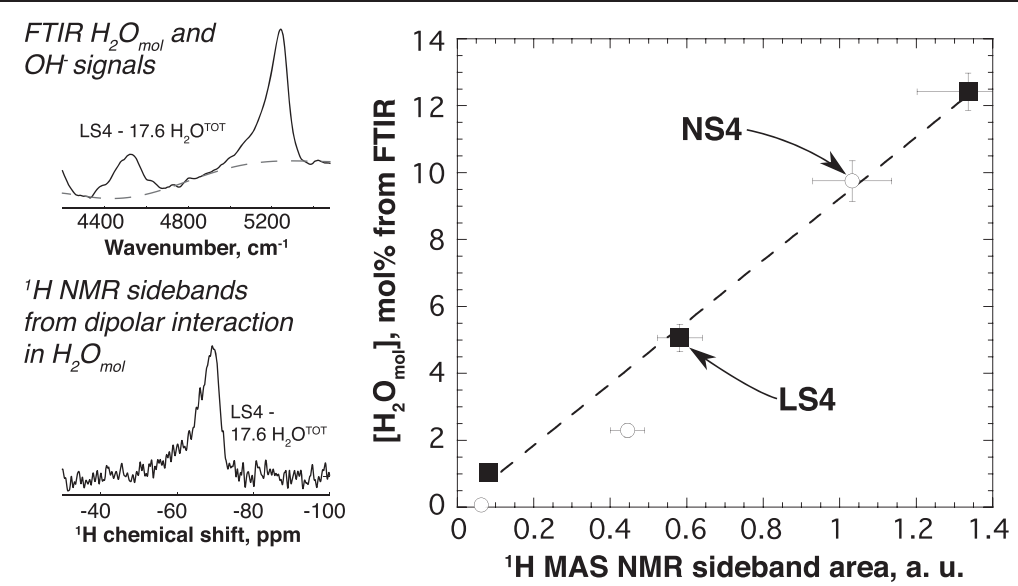

Fig. 1 Relationship between the area of ${ }^{1} \mathrm{H}$ MAS NMR sidebands, which arise from ${ }^{1} \mathrm{H}^{1}{ }^{1} \mathrm{H}$ dipolar interaction in $\mathrm{H}_{2} \mathrm{O}_{\text {mol }}$ species, and the concentration of the latters as measured by IR spectroscopy in the LS4 (plain squares) and NS4 (open circles) glasses. On the left, examples of the 4500 and $5200 \mathrm{~cm}^{-1} \mathrm{IR}$ combination bands, assigned to $\mathrm{OH}$ and $\mathrm{H}_{2} \mathrm{O}_{\text {mol }}$ species, respectively, and of one ${ }^{1} \mathrm{H}$ NMR sideband are shown for the LS4 glass containing $17.6 \mathrm{nom}$. mol\% water. On the FTIR example, the plain line represents the experimental spectrum and the dashed line is a polynomial baseline defining the background (see text)

combination band cannot be used for measuring the concentration of $\mathrm{OH}$ groups. In such cases, an alternative to derive $\mathrm{H}_{2} \mathrm{O}_{\text {mol }} / \mathrm{OH}$ is to use the sidebands in ${ }^{1} \mathrm{H}$ MAS NMR spectra. These sidebands are residual signals from ${ }^{1} \mathrm{H}-{ }^{1} \mathrm{H}$ dipolar coupling, this interaction being strongly averaged by the fast magic angle spinning in the present experiments. The ${ }^{1} \mathrm{H}_{-}{ }^{1} \mathrm{H}$ dipolar coupling is very strong in the case of $\mathrm{H}_{2} \mathrm{O}_{\text {mol }}$ species and negligible in the case of isolated $\mathrm{OH}$ groups (Eckert et al. 1988). Therefore, in normalized ${ }^{1} \mathrm{H}$ NMR spectra acquired under similar conditions, sideband area would express the fraction of $\mathrm{H}_{2} \mathrm{O}_{\text {mol }}$ species. Following this idea, Fig. 1 shows that the area of the sidebands $\left(\mathrm{A}_{\text {sidebands }}\right)$ of the ${ }^{1} \mathrm{H}$ MAS NMR spectra of LS4 and NS4 glasses, from Le7\#146;Losq et al. (2015a), seem to be a linear function of the glasses $\mathrm{H}_{2} \mathrm{O}_{\text {mol }}$ concentrations measured by IR. Particularly, the relationship seems nearly perfect for LS4 glasses. Slight deviations are observed for NS4 glasses. This can be rationalized with considering that most of the signal from $\mathrm{O}-\mathrm{H}$ stretching vibrations is located above $3000 \mathrm{~cm}^{-1}$ in the IR spectra of LS4 glasses whereas it slightly extends toward lower frequency in the IR spectra of NS4 glasses (Le Losq et al. 2015b). This results in better defined $\sim 4500$ and $\sim 5200 \mathrm{~cm}^{-1}$ combination bands in IR spectra of LS4 glasses than in those of NS4 glasses (Le Losq et al. 2015b), and hence, in higher accuracy on the calculated $\left[\mathrm{H}_{2} \mathrm{O}_{\text {mol }}\right]$ concentrations. Because of that, we can take the IR-based $\mathrm{H}_{2} \mathrm{O}_{\text {mol }}$ concentrations and $\mathrm{A}_{\text {sidebands }}$ from LS4 glasses as standards. Doing so, we obtain the relationship: mol \% $\mathrm{H}_{2} \mathrm{O}_{\text {mol }}=9.21 \pm 0.21 \times \mathrm{A}_{\text {sidebands. }}$ This equation allows us to determine the concentration of $\mathrm{H}_{2} \mathrm{O}_{\text {mol }}$ species and of $\mathrm{OH}$ groups (by difference to the total water content) in the KS4 glasses (Table 2).

\section{Results}

\section{Raman spectroscopy}

The Raman-active vibrational modes of the silicate tetrahedral network give rise to numerous bands between 400 and $1400 \mathrm{~cm}^{-1}$ in the Raman spectra of silicate glasses (Fig. 2). A strong band near $\sim 500 \mathrm{~cm}^{-1}$ is always observed. Smaller peaks and shoulders near 550 and $590-600 \mathrm{~cm}^{-1}$ are also present. Their intensity and frequency depend on glass composition. The respective intensity and frequencies of the contributions located between 450 and $650 \mathrm{~cm}^{-1}$ depend on the water content of the glasses and on the type of alkali metal (Fig. 2). Those signals arise from the bending/breathing modes of $\mathrm{Si}-\mathrm{O}-\mathrm{Si}$ bonds that link $Q^{n}$ units (noted " $Q{ }^{n}-Q^{n}$ modes" in Fig. 2; see for instance Bell et al. 1968; Sen and Thorpe 1977; Furukawa et al. 1981 or McMillan 1984).

A band near $800 \mathrm{~cm}^{-1}$ is also observed in all of the Raman spectra (Fig. 2). For a given alkali, the intensity of this peak changes with water content, but not its shape. At given water content, increasing ionic radius of alkali results in decreasing the intensity of this peak. This band may arise from vibrations involving the motion of the Si in its oxygen cage (McMillan 1984), this being possibly related to the threefold-degenerate "rigid cage" vibrational mode of $\mathrm{SiO}_{2}$ tetrahedra (Sen and Thorpe 1977; Galeener 1979). However, its origin is not firmly established. 


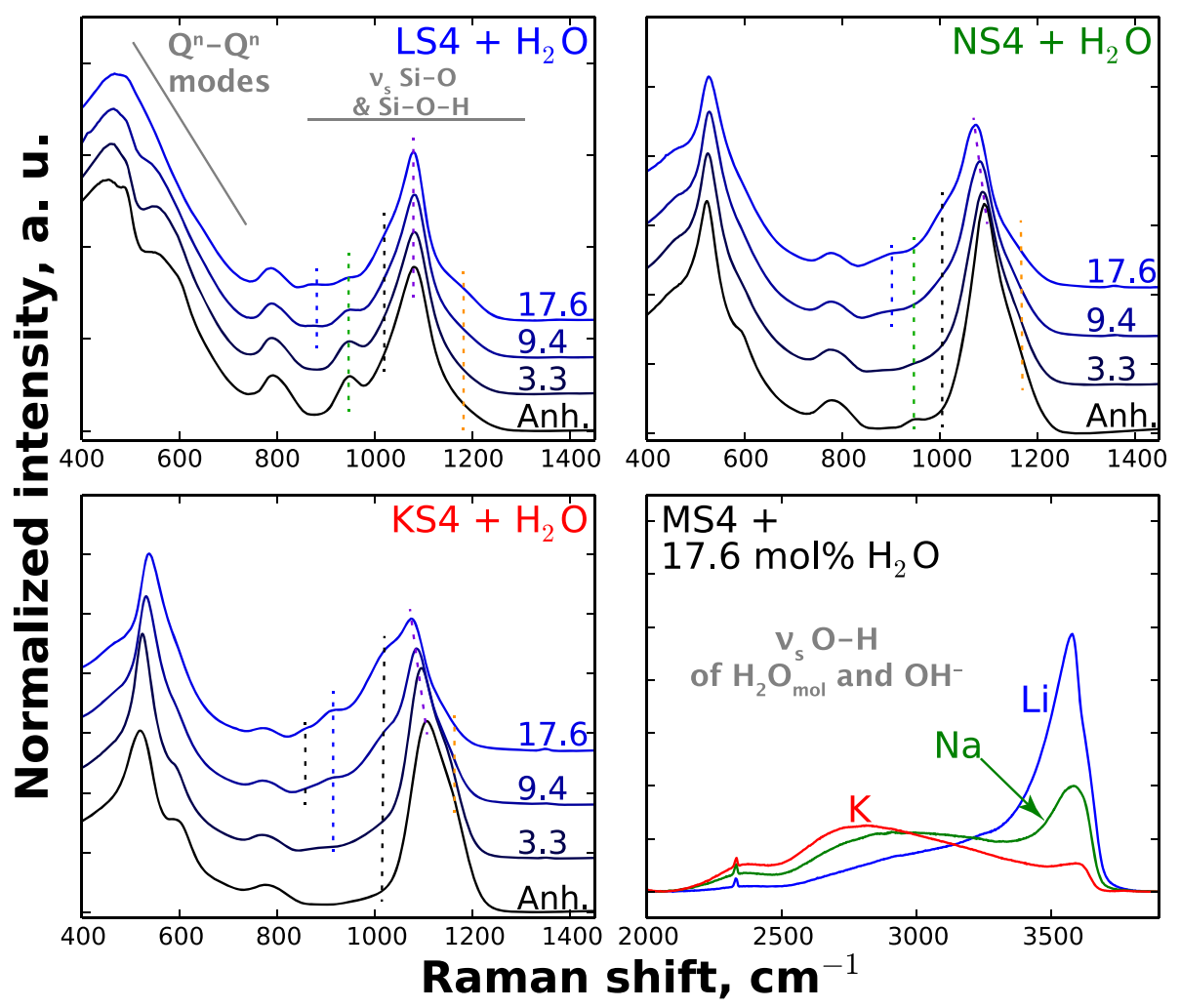

Fig. 2 Raman spectra of the lithium (LS4), sodium (NS4), and potassium (KS4) tetrasilicate glasses with 0.0 (Anh.), 3.3, 9.4, and 17.6 nom. mol \% $\left[\mathrm{H}_{2} \mathrm{O}^{\mathrm{TOT}}\right]$. Raman intensities are offset vertically for a better visibility, with the exception of the figure in bottom right. Dashed lines are used as visual markers of the signals contributing in the $820-1350 \mathrm{~cm}^{-1}$ portion of the spectra (see text). The small sharp peak located near $2330 \mathrm{~cm}^{-1}$ in the lower right figure is a signal from atmospheric $\mathrm{N}_{2}$

Signals assigned to $\mathrm{Si}-\mathrm{O}$ stretch vibrations in various $Q^{n}$ units ( $v_{\mathrm{s}} \mathrm{Si}-\mathrm{O}$ in Fig. 2) form the broad envelope of bands between 850 and $1300 \mathrm{~cm}^{-1}$ (Brawer and White 1975, 1977; Virgo et al. 1980; Mysen et al. 1982; McMillan 1984; Neuville et al. 2014 and references therein). In hydrous alkali silicate glasses, a band often assigned to $\mathrm{Si}-\mathrm{O}-\mathrm{H}$ stretch vibrations contributes to the intensity in the 900-970 $\mathrm{cm}^{-1}$ frequency range (Stolen and Walrafen 1976; McMillan et al. 1993; Zotov and Keppler 1998; Malfait 2009). At frequencies higher than $1300 \mathrm{~cm}^{-1}$, bands are observed between 2000 and $4000 \mathrm{~cm}^{-1}$ (Fig. 2, bottom right). These are assigned to $\mathrm{O}-\mathrm{H}$ stretching $\left(v_{\mathrm{s}} \mathrm{O}-\mathrm{H}\right)$ in $\mathrm{H}_{2} \mathrm{O}_{\text {mol }}$ and $\mathrm{OH}$ groups (Scholtze 1960; Bartholomew et al. 1980; Wu 1980; Zotov and Keppler 1998). Their intensity and frequency depend on the chemical composition of the alkali silicate glasses. The larger the alkali ionic radius $r$, the lower the O-H stretch frequency (Fig. 2; see also Le Losq et al. 2015a; Le Losq et al. 2015b).

The topology of the $850-1300 \mathrm{~cm}^{-1}$ frequency region of the Raman spectra systematically varies as a function of both water content and ionic field strength of alkali in the glass (Fig. 2). This variation likely reflects changes of the $Q^{n}$ species fractions. To quantify those changes, this portion of Raman spectra was fitted with Gaussian peaks. Such peak shape was used because it returns the best fitting results compared to other peak shapes (e.g., Lorentzian or Pseudo-Voigt shapes). This conclusion also is coherent with an expected pseudo Boltzmann distribution of Si$\mathrm{O}$ vibrators in silicate melts in regards of their high thermal agitation and structural disorder at the glass transition temperature (Mysen et al. 1982). Table 3 summarizes the peaks used to perform the fits as well as their assignments and the references that substantiate those assignments.

The peak near $1100 \mathrm{~cm}^{-1}$ is assigned to $\mathrm{Si}-\mathrm{O}$ stretching in $Q^{3}$ species. It is the most intense signal in the Raman spectra of all anhydrous glasses, whatever the alkali metal (Figs. 3 and 4). Areas of the peaks assigned to Si$O$ stretching in $Q^{2}$ and $Q^{4}$ species (near 950 and 1150$1200 \mathrm{~cm}^{-1}$ ) respectively decrease and increase with increasing ionic radius of the alkali cation. These intensity variations indicate variations in the $Q^{n}$ distribution as a function of the alkali ionic radius/field strength, similar 
Table 3 Assignment of the peaks from curve-fitted Raman spectra

\begin{tabular}{|c|c|c|}
\hline Raman shift, $\mathrm{cm}^{-1}$ & Attribution & Source \\
\hline$\sim 850 \mathrm{~cm}^{-1}$ & $v_{5}$ Si-O in $Q^{1}$ & $\begin{array}{l}\text { Furukawa et al. (1981), Virgo } \\
\text { et al. (1980), Mysen et al. } \\
\text { (1982), McMillan (1984) }\end{array}$ \\
\hline$\sim 880-910 \mathrm{~cm}^{-1}$ & $v_{s} \mathrm{Si}-\mathrm{O}-\mathrm{H}$ & $\begin{array}{l}\text { McMillan et al. (1993), Zotov } \\
\text { and Keppler (1998), Malfait } \\
\text { (2009), Spiekermann et al. } \\
\text { (2012) }\end{array}$ \\
\hline$\sim 960 \mathrm{~cm}^{-1}$ & $v_{s} S i-O$ in $Q^{2}$ & $\begin{array}{l}\text { Brawer and White (1975), } \\
\text { Brawer and White (1977), } \\
\text { Virgo et al. (1980), Furukawa } \\
\text { et al. (1981), Mysen et al. } \\
\text { (1982), McMillan (1984) }\end{array}$ \\
\hline$\sim 1020 \mathrm{~cm}^{-1}$ & $v_{s} S i-B O$ in $Q^{n}$ & $\begin{array}{l}\text { Mysen et al. (1982), } \\
\text { Spiekermann et al. (2012), } \\
\text { Le Losq and Neuville (2013) }\end{array}$ \\
\hline$\sim 1090 \mathrm{~cm}^{-1}$ & $v_{s}$ Si-O in $Q^{3}$ & $\begin{array}{l}\text { Brawer and White (1975), } \\
\text { Virgo et al. (1980), Furukawa } \\
\text { et al. (1981), Mysen et al. } \\
\text { (1982) }\end{array}$ \\
\hline$\sim 1140 \mathrm{~cm}^{-1}$ & $v_{s} \operatorname{Si}-O$ in $Q^{4, \|}\left({ }^{a}\right)$ & $\begin{array}{l}\text { Mysen et al. (1982), Seifert } \\
\text { et al. (1982), Mysen (1990), } \\
\text { Neuville and Mysen (1996), } \\
\text { Le Losq and Neuville (2013), } \\
\text { Le Losq et al. (2014) }\end{array}$ \\
\hline$\sim 1190 \mathrm{~cm}^{-1}$ & $v_{s} \operatorname{Si}-O$ in $Q^{4, l}\left({ }^{a}\right)$ & $\begin{array}{l}\text { Mysen et al. (1982), Seifert } \\
\text { et al. (1982), Mysen (1990), } \\
\text { Neuville and Mysen (1996), } \\
\text { Le Losq and Neuville (2013), } \\
\text { Le Losq et al. (2014) }\end{array}$ \\
\hline
\end{tabular}

${ }^{a}$ Two Gaussians named $Q^{4, I}$ and $Q^{4, I}$ are used for fitting the Si-O stretch of $Q^{4}$ because of its non-Gaussian shape. See Mysen et al. (1982), Seifert et al. (1982), Neuville and Mysen (1996), and Le Losq and Neuville (2013) for further discussion on this topic. In more depolymerized glasses, the signal of $Q^{4}$ becomes weak and only one band is needed (see in Fig. 2 the spectrum of $\mathrm{KS} 4+17.6 \mathrm{~mol} \% \mathrm{H}_{2} \mathrm{O}$ for instance)

to the conclusions drawn from previous ${ }^{29} \mathrm{Si} \mathrm{NMR} \mathrm{(e.g.,}$ Maekawa et al. 1991) and Raman (e.g., Matson et al. 1983; Mysen 1990) spectra of binary alkali silicate glasses.

Solution of water in the melts quenched to glasses results in the appearance in the Raman spectra of a new peak near $900 \mathrm{~cm}^{-1}$ (Fig. 3). Its intensity increases with increasing water content, but the extent of this change depends on ionic radius of alkali (Fig. 3). The greater the alkali ionic radius, the larger the intensity of the $\sim 900 \mathrm{~cm}^{-1}$ peak. Moreover, it appears that the type of alkali in the glass affects the frequency of this peak. For example, in the Raman spectra of glasses with $17.6 \mathrm{~mol} \% \mathrm{H}_{2} \mathrm{O}$, it shifts from $882 \mathrm{~cm}^{-1}$ for LS4 to $902 \mathrm{~cm}^{-1}$ for NS4 and $918 \mathrm{~cm}^{-1}$ for KS4. According to the study of Zotov and Keppler (1998) on sodium silicate glasses, this $\sim 900 \mathrm{~cm}^{-1}$ peak may be assigned to $\mathrm{Si}-\mathrm{O}-\mathrm{H}$ stretching vibrations in $Q^{n}$ species with $\mathrm{Si}-\mathrm{O}-\mathrm{H}$ bonds, regardless their number of bridging oxygens $n$. In pure hydrous silica, a peak near $976 \mathrm{~cm}^{-1}$ has been assigned to the signal of Si-O-H stretching vibrations (Stolen and Walrafen
1976). In hydrous aluminosilicate glasses, a peak located near $900 \mathrm{~cm}^{-1}$ has been assigned to a mixture of $\mathrm{Si}-\mathrm{O}-\mathrm{H}$ and $\mathrm{Al}-\mathrm{O}-\mathrm{H}$ vibrations, with the assumption that the Al-O$\mathrm{H}$ stretching frequency is lower than that of $\mathrm{Si}-\mathrm{O}-\mathrm{H}$ (McMillan et al. 1993; Malfait 2009). However, recent results from molecular dynamic simulations (Spiekermann et al. 2012) questioned the attribution of the $976 \mathrm{~cm}^{-1}$ signal in pure hydrous silica and suggested that this peak may actually arise from the asymmetric $\mathrm{Si}-\mathrm{O}$ stretching vibration of $Q^{2}$ units and that the $\mathrm{Si}-\mathrm{O}-\mathrm{H}$ stretching signal may form a shoulder near $920 \mathrm{~cm}^{-1}$ on the side of the $976 \mathrm{~cm}^{-1}$ peak. The fact that a peak near $900 \mathrm{~cm}^{-1}$ is detected and grows with solution of water in silicate glasses (Figs. 2 and 3, see also Zotov and Keppler 1998) may support such an interpretation, at least for silicate glasses.

The area of the $\sim 950 \mathrm{~cm}^{-1}$ peak, assigned to $\mathrm{Si}-\mathrm{O}$ stretching vibrations in $Q^{2}$, increases with solution of water in KS4 and NS4 glasses but decreases slightly in spectra of LS4 glasses (Fig. 4). The area of the $\sim 1100 \mathrm{~cm}$ ${ }^{-1}$ peak, assigned to $\mathrm{Si}-\mathrm{O}$ stretching vibrations in $Q^{3}$, seems to increase slightly with solution of water, but this effect is small ( $\leq 6 \%$ with addition of $17.6 \mathrm{~mol} \% \mathrm{H}_{2} \mathrm{O}$, Fig. 4). Finally, the area of the two peaks at $\sim 1150$ and $1200 \mathrm{~cm}^{-1}$, assigned to $\mathrm{Si}-\mathrm{O}$ stretching vibrations in $Q^{4}$, varies differently as a function of water concentration and alkali ionic radius (Fig. 4). In Raman spectra of the NS4 and KS4 glasses, the area of these two peaks decreases with increasing water content $(\sim 10-20 \%$ with addition of $\left.17.6 \mathrm{~mol} \% \mathrm{H}_{2} \mathrm{O}\right)$. In contrast, their area increases slightly $(\sim 3 \%)$ with increasing water content from 0.0 up to $17.6 \mathrm{~mol} \%$ in LS4 glasses.

There is another peak, near $850 \mathrm{~cm}^{-1}$, in spectra of the KS4 glasses at high water concentration (Figs. 2 and 3). Its origin could be related to the presence of $Q^{1}$ species (e.g., see Mysen et al. 1982 or McMillan 1984), but $Q^{1}$ species are not detected by ${ }^{29} \mathrm{Si}$ NMR spectroscopy (see below and Fig. 5). This could be explained by an enhanced Raman signal of $Q^{1}$ species compared to other more polymerized $Q^{2}$, $Q^{3}$, or $Q^{4}$ species because of the increase of the Raman cross section of $Q^{n}$ units that results from their depolymerization (decreasing $n$; see for instance Furukawa et al. 1981). Such effect has been observed for $Q^{2}$ species in sodium silicate glasses (Le Losq et al. $2014)$. Therefore, a very small proportion of $Q^{1}$ species $(<1 \%)$ may be present in the $\mathrm{KS} 4+17.6 \mathrm{~mol} \% \mathrm{H}_{2} \mathrm{O}$ and undetected by ${ }^{29} \mathrm{Si}$ NMR spectroscopy. This interpretation is speculative but does not affect the global observations because the $850 \mathrm{~cm}^{-1}$ signal intensity is negligible compared with those of the other signals.

\section{${ }^{29} \mathrm{Si}$ single-pulse (SP) MAS NMR spectra}

The ${ }^{29}$ Si SP MAS NMR spectra of anhydrous glasses comprise two main peaks near -95 and -105 ppm 


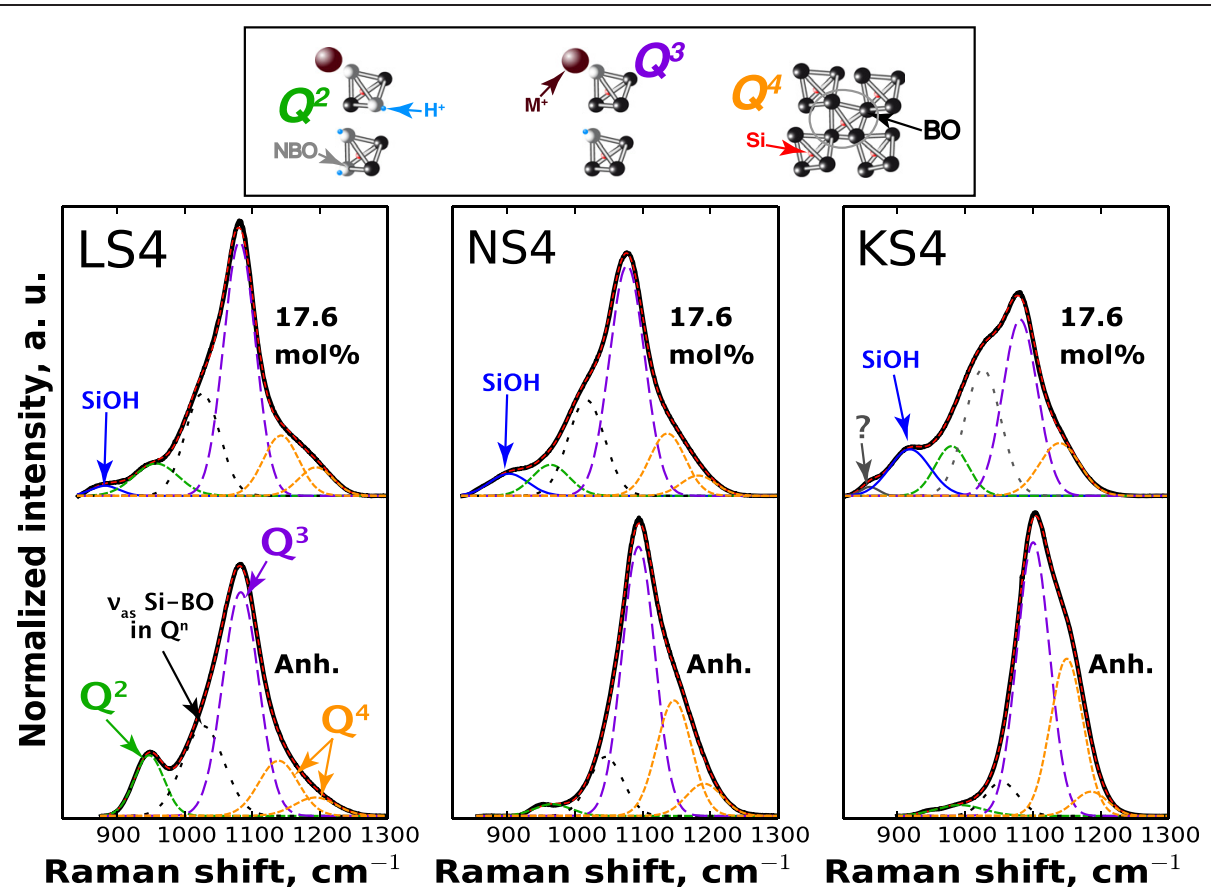

Fig. 3 Examples of curve-fitted Raman spectra of anhydrous and 17.6 mol\% $\mathrm{H}_{2} \mathrm{O}$ LS4 (left), NS4 (middle), and KS4 (right) glasses. Addition of water in the glasses clearly produces an increasing intensity near $900 \mathrm{~cm}^{-1}$. It could be related to the stretching signal of Si-O-H bonds regardless of the $Q^{n}$ specie carrying those bonds. Signal near $850 \mathrm{~cm}^{-1}$ in the Raman spectrum of $\mathrm{KS} 4+17.6 \mathrm{~mol} \% \mathrm{H}_{2} \mathrm{O}$ glass may be related to $Q^{l}$ species in the glass in negligible quantities. The various $Q^{n}$ species are schematically represented at the top of the figure (ionic size is not at scale). BO bridging oxygen (Si-O-Si bonds), NBO non-bridging oxygen (Si-O-M or Si-O-H bonds, with $\mathrm{M}^{+}$an alkali)

(Fig. 5). A third contribution, located near $-85 \mathrm{ppm}$, forms a shoulder in the spectrum of the anhydrous LS4 glass. The $\sim-105,-95$, and $-85 \mathrm{ppm}$ contributions are assigned to the signals of ${ }^{29} \mathrm{Si}$ in $Q^{4}, Q^{3}$, and $Q^{2}$ species, respectively (Lippmaa et al. 1980; Murdoch et al. 1985; Maekawa et al. 1991). The $Q^{3}$ and $Q^{4}$ contributions dominate the ${ }^{29} \mathrm{Si}$ SP MAS NMR spectra of anhydrous glasses (Fig. 5), in agreement with interpretation of Raman data (Figs. 3 and 4). The signal of $Q^{2}$ species is visible only in the spectrum of the LS4 anhydrous glass (Fig. 5). The relative intensities of $Q^{3}$ and $Q^{429} \mathrm{Si}$ NMR signals vary slightly with ionic radius of alkali in anhydrous glasses. The global width of the ${ }^{29} \mathrm{Si}$ NMR signal also decreases with increasing ionic radius of alkali metal, and the frequency difference between $Q^{3}$ and $Q^{4}$ signals narrows (Fig. 5). The $Q^{4}$ frequency is the lowest in the spectrum of LS4 glass compared with those in the spectra of the NS4 and KS4 glasses. Such ${ }^{29} \mathrm{Si}$ NMR frequency changes can result from a modification of the shielding of the ${ }^{29} \mathrm{Si}$ nuclei with changing ionic radius of alkali. Maekawa et al. (1991) suggested that such shielding evolution may reflect changes in the third neighbor environments (e.g., Olivier et al. 2001), bond length, or bridging $\mathrm{Si}-\mathrm{O}-\mathrm{Si}$ angle as a function of ionic radius of alkali in silicate glasses.

In order to highlight the perturbations induced by the water addition in the glasses networks, the ${ }^{29} \mathrm{Si}$ SP MAS
NMR spectra of the anhydrous glasses have been subtracted from those of hydrous glasses, giving residual ${ }^{29} \mathrm{Si}$ NMR spectra where positive and negative peaks can be observed (Fig. 5, bottom). Those peaks represent the changes of the proportions in the various $Q^{n}$ species upon water addition. In all glasses, solution of water results in a reduction in intensity of the $Q^{4}$ peak, whereas that of the $Q^{3}$ peak increases (Fig. 5). However, the extent of this intensity change depends on ionic radius of alkali metal. The $Q^{3} / Q^{4}$ ratio changes only slightly for LS4 glass, whereas it increases strongly for KS4 glass. In the NMR spectra of NS4 and KS4 glasses, the intensity near $-80 /-85 \mathrm{ppm}$ also increases upon water solution but not in spectra of LS4 glasses. It follows, therefore, that upon solution of water in the silicate glasses, $Q^{4}$ units are converted to $Q^{3}$ and $Q^{2}$ units, and that this effect gets more pronounced with increasing ionic radius of alkali.

\section{Quantification of the effect of water on glass polymerization}

The relative areas, $A_{Q^{n}}\left(\sum_{n=0}^{4} A_{Q^{n}}=1\right)$, of the Raman peaks assigned to Si-O stretching in $Q^{n}$ units (Fig. 4) can be related to the fraction of $Q^{n}$ units through (Mysen 1990; Mysen and Frantz 1993): 


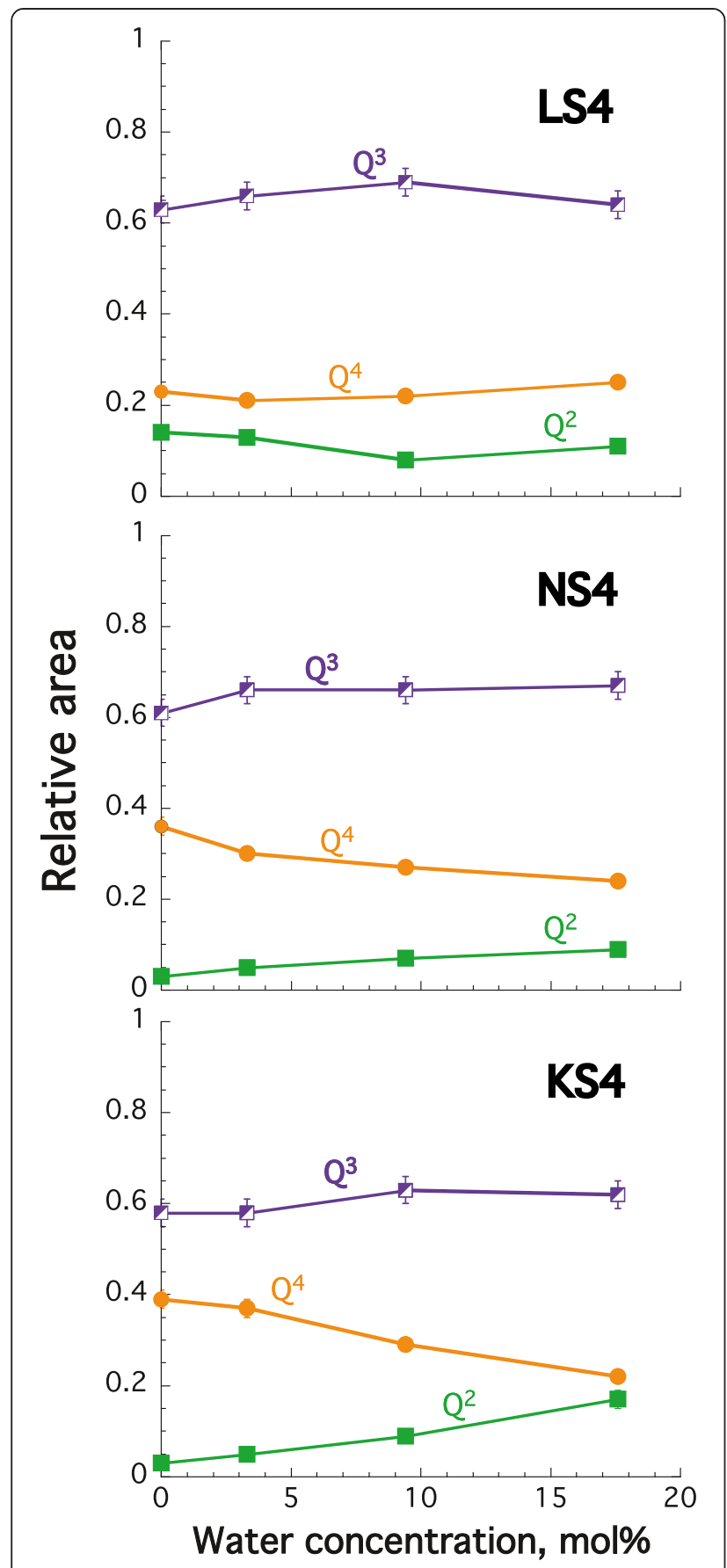

Fig. 4 Relative area of the Raman signals assigned to $Q^{2}, Q^{3}$, and $Q^{4}$ units composing the LS4 (top), NS4 (middle), and KS4 (bottom) glasses as a function of their nominal water concentration. Errors are given at the $1 \sigma$ confidence interval. If not visible, they are smaller than the symbol sizes

$$
\left[Q^{n}\right]=\theta^{n} A_{Q^{n}}
$$

with $\theta^{n}$ a conversion factor that directly depends on the Raman cross section of the $\mathrm{Si}-\mathrm{O}$ stretching vibrations in the $Q^{n}$ units. The polymerization of a glass that contains a mixture of $Q^{2}, Q^{3}$ and $Q^{4}$ units can be quantified by calculating the ratio of the mean number of NBOs other tetrahedral BOs as:

$$
\mathrm{NBO} / \mathrm{T}=2\left[Q^{2}\right]+\left[Q^{3}\right]=2 \times \theta^{2} A_{Q^{2}}+\theta^{3} A_{Q^{3}}
$$

Between the anhydrous and hydrous glasses, we have the following equation:

$$
\Delta \mathrm{NBO} / \mathrm{T}=\mathrm{NBO} / \mathrm{T}^{\text {hyd }}-\mathrm{NBO} / \mathrm{T}^{\text {anh }}=2\left[\Delta \mathrm{Q}^{2}\right]+\left[\Delta \mathrm{Q}^{3}\right],
$$

where $\Delta Q^{2}$ and $\Delta Q^{3}$ are the variations of the $Q^{2}$ and $Q^{3}$ fractions between the anhydrous and hydrous glasses. The $\theta^{2}$ and $\theta^{3}$ values are near unity for sodium silicates and the effect of water solution on those values is negligible (Mysen 2007). Therefore, as a first approximation, we can neglect the $\theta^{2}$ and $\theta^{3}$ factors in Eqs. (5) and (6). It follows from the Raman data that addition of $17.6 \mathrm{~mol} \%$ water in the LS4, NS4, and KS4 glasses results in $\triangle N B O / T$ of $-0.04 \pm 0.05,0.18 \pm 0.05$, and $0.30 \pm 0.05$, respectively (Table 4).

Fitting ${ }^{29} \mathrm{Si}$ SP MAS NMR spectra with a set of Gaussian lines usually allows quantification of the $Q^{n}$ fractions in silicate glasses (e.g., Maekawa et al. 1991). However, fitting the ${ }^{29} \mathrm{Si}$ SP MAS NMR spectra of the hydrous glasses is difficult because of the poor resolution of the shoulder associated to the signal of ${ }^{29} \mathrm{Si}$ in $Q^{2}$ units. Several solutions can be returned by the fitting procedure, and it is not clear how to discriminate between them. Fortunately, spectral fitting is not a requirement for quantifying the polymerization change induced by solution of water in glasses. Indeed, the areas of the peaks assigned to $Q^{2}, Q^{3}$, and $Q^{4}$ units in the residual ${ }^{29}$ Si SP MAS NMR spectra (Fig. 5, bottom) are equivalent to the fractions of transformed $Q^{n}$ units $\left(\Delta Q^{n}\right)$ upon solution of water. For the LS4 glasses, the $\Delta Q^{3}$ signal area was measured between -87 and $-102 \mathrm{ppm}$ and the $\Delta Q^{4}$ signal area between -102 and $-122 \mathrm{ppm}$. In the spectra of the NS4 glasses, areas of the $\Delta Q^{2}, \Delta Q^{3}$, and $\Delta Q^{4}$ signals were measured from -70 to $-88,-88$ to -101 , and -101 to -120 , respectively. For the spectra of KS4 glasses, the areas were measured from -70 to $-91,-91$ to -100 , and -100 to -120 , respectively. In order to evaluate the errors affecting the area determinations, the boundaries reported above were varied in a $\pm 2-3 \mathrm{ppm}$ uncertainty range. We have chosen such an uncertainty range because it is similar to the variations that affect the frequency of the peaks observed on the ${ }^{29}$ Si MAS NMR spectra of the various glasses, and because it produces residual intensity variations higher than the noise level. As a result, such uncertainty range appears to be the best estimate for estimating the errors affecting the areas of residual signals. 


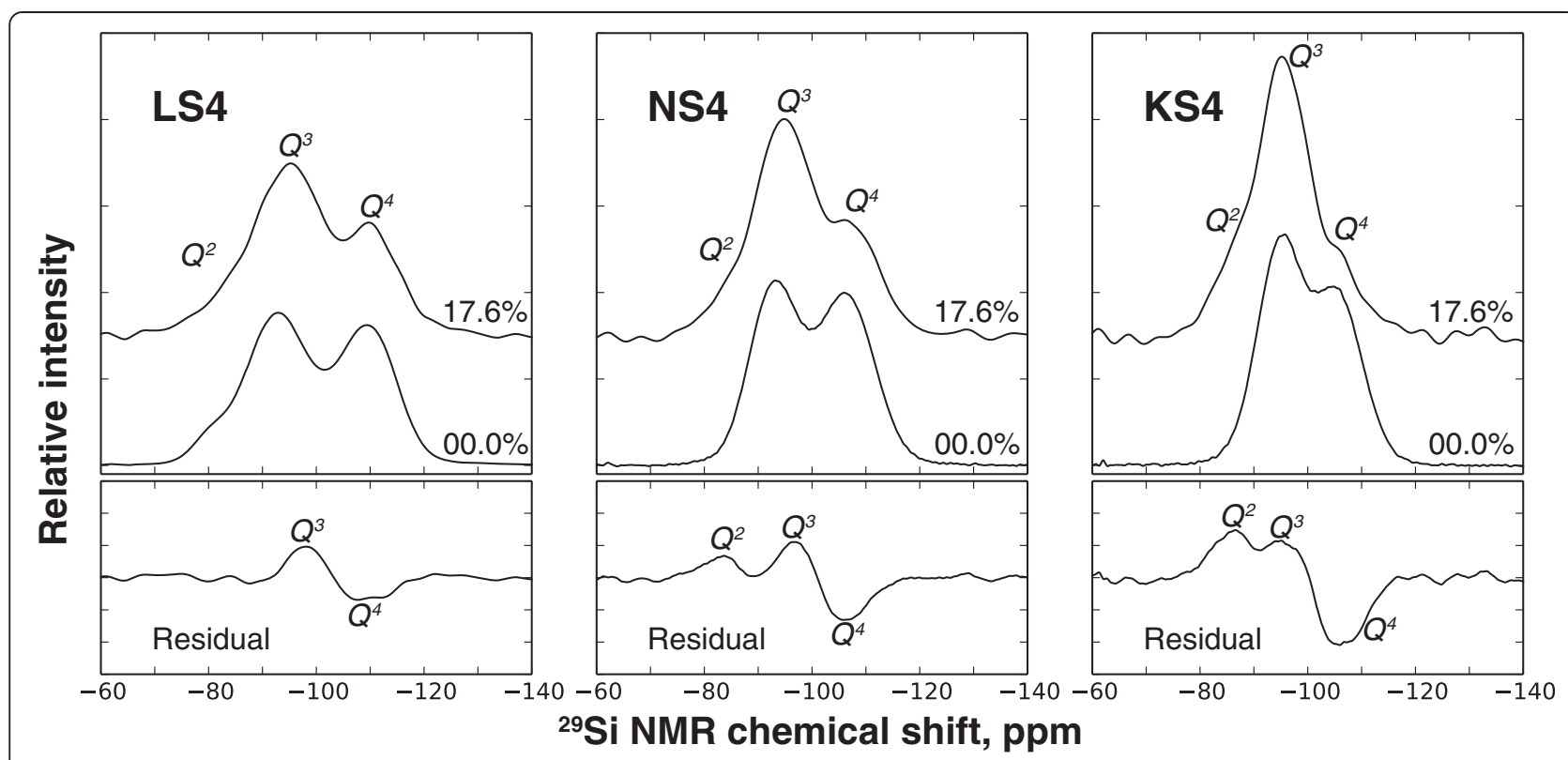

Fig. 5 Top: ${ }^{29} \mathrm{Si}$ single-pulse MAS (5 kHz) NMR spectra of the anhydrous and 17.6 nom. mol \% $\mathrm{H}_{2} \mathrm{O}$ LS4 (left), NS4 (middle), and KS4 (right) glasses. Intensities on spectra are normalized such that the total areas of the spectra are equal to unity. Changes in relative intensity and areas are thus directly proportional to the changes in the chemical concentrations of ${ }^{29} \mathrm{Si}$ in particular $Q^{n}$ species. Bottom: residuals from the subtraction of the ${ }^{29} \mathrm{Si}$ NMR signals from hydrous glasses minus those from anhydrous glasses. Areas under the positive and negative peaks are quantitative and represent the fraction of transformed $Q^{n}$ species upon hydration

The $\Delta Q^{2}$ and $\Delta Q^{3}$ values thus obtained can be used to compute $\triangle N B O / T$ with Eq. (6). The $\triangle N B O / T$ calculated from Raman data and from ${ }^{29}$ Si SP MAS NMR difference spectra are in good agreement (Fig. 6 and Table 4) except for LS4 glass. Indeed, for the latter, the $\triangle N B O / T$ values obtained with the two different spectroscopic methods are different: $-0.04 \pm 0.05$ (Raman) and $0.07 \pm 0.01$ (NMR). The $Q^{n}$ speciation derived from the Raman spectra of LS4 glasses suggests almost no depolymerization of those glasses upon water solution. This conclusion differs somewhat from that drawn from the ${ }^{29} \mathrm{Si}$ NMR data, which indicate that there is a weak, but real, effect of water on the polymerization of LS4 glasses (Fig. 5). The errors affecting the fitting of Raman spectra might be too large to allow detection of the weak effect of water solution on the structure of LS4 glasses. Indeed, the Raman-derived $\triangle N B O / T$ values are affected by errors inherent to the fitting procedure (optimization error) as well as by errors inherent to the initial assumptions made for fitting (e.g., perfect Gaussian shape for the peaks). In this regards, NMR-derived $\triangle N B O / T$ values are more robust than the Raman-derived $\triangle N B O / T$ values because they do not rely on any fitting procedure but directly on calculations from raw data. This notwithstanding, both sets of values indicate a small effect of water addition on the degree of polymerization of the LS4 composition.

Table $4 \Delta \mathrm{NBO} / \mathrm{T}$, concentrations of total $\mathrm{OH}$ groups, $\mathrm{SiOH}$, and unknown $\mathrm{OH}$ groups

\begin{tabular}{|c|c|c|c|c|c|c|c|c|}
\hline & $\begin{array}{l}\mathrm{H}_{2} \mathrm{O}^{\mathrm{TOT}} \\
\text { (Raman) }\end{array}$ & {$[\mathrm{OH}]$} & $\begin{array}{l}\mathrm{N} \mathrm{NBO} / \mathrm{T} \\
\text { (Raman) }\end{array}$ & $\begin{array}{l}{[\mathrm{SiOH}]} \\
\text { (Raman) }\end{array}$ & $\begin{array}{l}\text { [Unknown OH] } \\
\text { (Raman) }\end{array}$ & $\begin{array}{l}\triangle \mathrm{NBO} / \mathrm{T} \\
(\mathrm{NMR})\end{array}$ & $\begin{array}{l}\mathrm{SiOH}] \\
(\mathrm{NMR}) \\
\end{array}$ & $\begin{array}{l}\text { [Unknown OH] } \\
\text { (NMR) }\end{array}$ \\
\hline \multirow[t]{3}{*}{ LS4 } & $3.08(60)$ & $2.11(35)$ & $0.02(5)$ & $0.63(1.25)$ & $1.47(3.41)$ & - & - & - \\
\hline & $10.09(60)$ & $4.56(70)$ & $-0.05(5)$ & $0.00(-)$ & $4.56(1.27)$ & - & - & - \\
\hline & $18.74(60)$ & $6.26(94)$ & $-0.04(5)$ & $0.00(-)$ & $6.26(1.57)$ & $0.07(1)$ & $2.77(16)$ & 3.49 (95) \\
\hline \multirow[t]{3}{*}{ NS4 } & $3.44(67)$ & $3.85(40)$ & 0.08 (5) & $3.24(66)$ & $0.61(77)$ & - & - & - \\
\hline & $9.46(67)$ & $7.35(63)$ & $0.13(5)$ & $5.02(43)$ & $2.33(76)$ & - & - & - \\
\hline & $17.54(67)$ & $9.52(80)$ & $0.18(5)$ & $7.28(30)$ & $2.24(85)$ & $0.18(1)$ & $7.17(5)$ & $2.35(80)$ \\
\hline \multirow[t]{3}{*}{ KS4 } & $3.98(74)$ & $3.98(70)$ & $0.04(4)$ & $1.42(1.22)$ & $2.56(40)$ & - & - & - \\
\hline & $9.46(74)$ & $8.89(70)$ & $0.15(5)$ & $5.88(32)$ & 3.01 (77) & - & - & - \\
\hline & $15.95(74)$ & $13.65(70)$ & $0.30(5)$ & 12.08 (19) & $1.57(72)$ & $0.34(2)$ & $13.63(7)$ & $0.02(70)$ \\
\hline
\end{tabular}




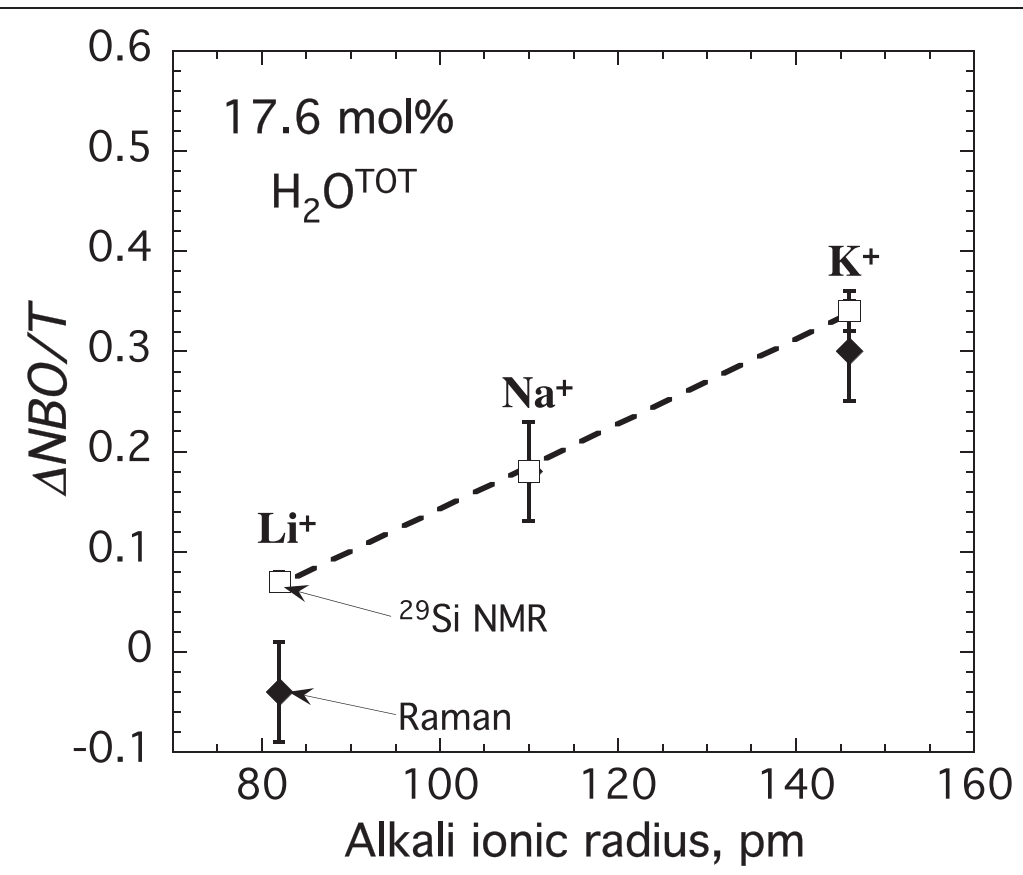

Fig. 6 Variation of the polymerization of the glasses $(\triangle \mathrm{NBO} / \mathrm{T})$ upon addition of $17.6 \mathrm{nom}$. mol \% water represented as a function of the ionic radius of alkali. $\triangle \mathrm{NBO} / \mathrm{T}$ ( $=\mathrm{NBO} / T_{\text {anhydrous }}-\mathrm{NBO} / \mathrm{T}_{17.6 \mathrm{~mol} \% \text { water }}$ is calculated from the variations of the $Q^{n}$ species as observed in Raman spectra (plain symbo/s) or in ${ }^{29} \mathrm{Si}$ NMR spectra (open symbols). Ionic radii of alkalis are from Whittaker and Muntus (1970), assuming sixfold oxygen-coordinated alkalis. The black dotted line is a linear fit of the $\triangle \mathrm{NBO} / T$ vs ionic radius relationship for NMR data. For the Na-bearing silicate glass, Raman and ${ }^{29} \mathrm{Si}$ NMR give the same value, so that symbols are difficult to distinguish. Error bars are given at the $1 \sigma$ confidence interval

\section{Discussion}

The dissolution of water into alkali silicate glasses results in their depolymerization, as shown by ${ }^{29} \mathrm{Si}$ NMR and Raman data (Figs. 4, 5, and 6). The $Q^{4}$ units transform to $Q^{3}$ and $Q^{2}$ units according to the reaction.

$$
Q^{4}<=>\phi Q^{2}+(1-\phi) Q^{3},
$$

where $\phi$ is a constant reflecting the partitioning of the NBOs (formed upon $\mathrm{H}_{2} \mathrm{O}$ addition) between $Q^{3}$ and $Q^{2}$. The equilibrium constant $K_{7}$ of reaction 7 depends on ionic radius of alkali. The larger the radius, the greater the $\triangle N B O / T$ and, thus, the higher the $K_{7}$ (Fig. 6). This dependence likely is linked to the influence of ionic radius of alkali metal on the $\mathrm{OH} / \mathrm{H}_{2} \mathrm{O}_{\text {mol }}$ ratio. At given water content, the larger the ionic size of alkali cation, the higher this ratio (Fig. 7). The variations of $\phi$ seem primarily related to the extent of depolymerization of the silicate network because the ratio $\Delta Q^{2} / \Delta Q^{3}$ is correlated with $\triangle N B O / T$. At low $\triangle N B O / T$, and hence for $N B O / \mathrm{T}$ close to $0.5, \phi$ is low and $Q^{3}$ units are produced by reaction (7). At high $\triangle N B O / T$, and hence for $N B O /$ $T>0.5, \phi$ is high and $Q^{2}$ units formation may dominate.

The concentration of $\mathrm{OH}$ groups that form $\mathrm{SiOH}$ bonds upon hydration of the glasses can be determined by using the $\triangle N B O / T$ values derived from the $Q^{n}$-species abundances. This is possible because oxygen in the

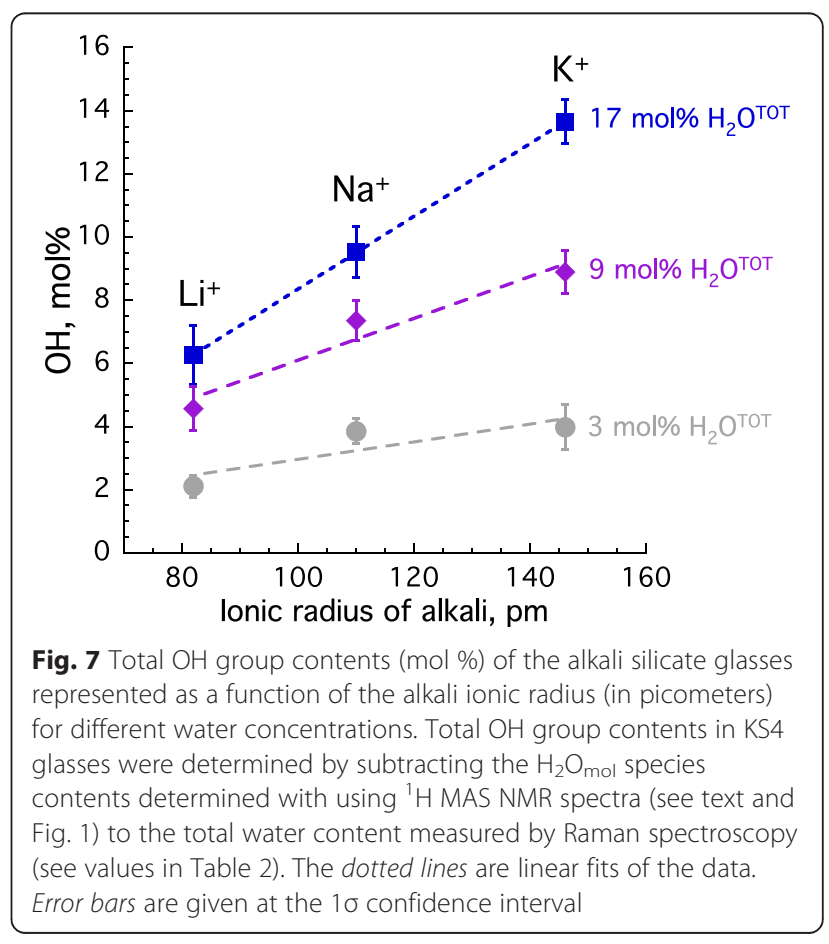




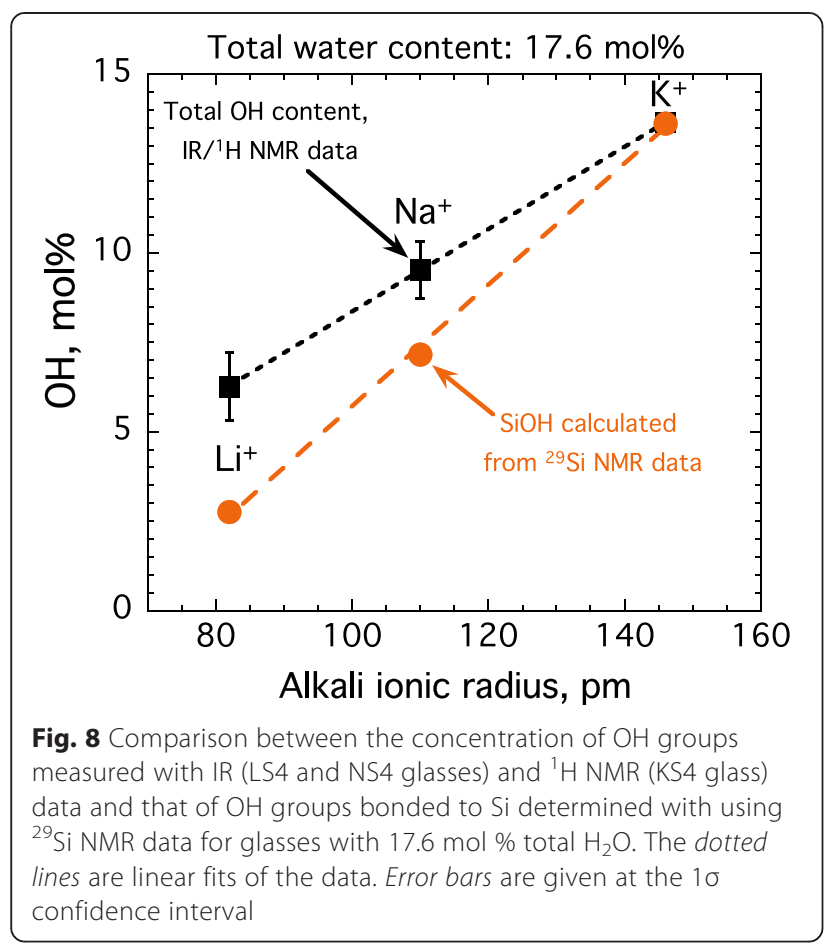

$\mathrm{SiOH}$ groups is non-bridging, so that $\mathrm{SiOH}$ group formation testifies to the depolymerization of the silicate network upon water solution (Eq. (2)). Figure 8 presents a comparison between the $\mathrm{SiOH}$ content determined with using $\triangle N B O / T$ derived from ${ }^{29} \mathrm{Si}$ SP MAS NMR data and the concentration of $\mathrm{OH}$ groups determined by using IR and ${ }^{1} \mathrm{H}$ MAS NMR data for glasses with $17.6 \mathrm{~mol} \%$ water. At this water content, it appears that there are significant differences between these two sets of values for hydrous NS4 and LS4 glasses. For those glasses, the concentrations of $\mathrm{SiOH}$ groups are lower than those of $\mathrm{OH}$ groups detected by IR and ${ }^{1} \mathrm{H}$ MAS NMR spectroscopy. For the KS4 glass with $17.6 \mathrm{~mol} \%$ water, the $\mathrm{SiOH}$ and the $\mathrm{OH}$ values obtained by the different methods agree. The $\mathrm{SiOH}$ fractions calculated from Raman-derived $\triangle N B O / T$ values confirm the above observations by showing a very similar trend following changes in ionic radius of alkali metal for glasses with 17.6 nom. mol \% $\left[\mathrm{H}_{2} \mathrm{O}^{\mathrm{TOT}}\right]$ (Table 4).

The comparison in Fig. 8 and Table 4 between the $\mathrm{SiOH}$ concentrations retrieved through the ${ }^{29} \mathrm{Si}$ NMR data, validated by Raman results, and the total $\mathrm{OH}$ concentration from IR spectroscopy indicates that there is a significant fraction of OH groups in the NS4 and LS4 glasses that do not reflect depolymerization of the silicate network and for which we do not know the nature of their bonding. At 17.6 nom. mol \% water, the concentration of those "unknown" $\mathrm{OH}$ groups increases with decreasing ionic radius, and hence, increasing ionic field strength of alkali metal (Fig. 9). It is

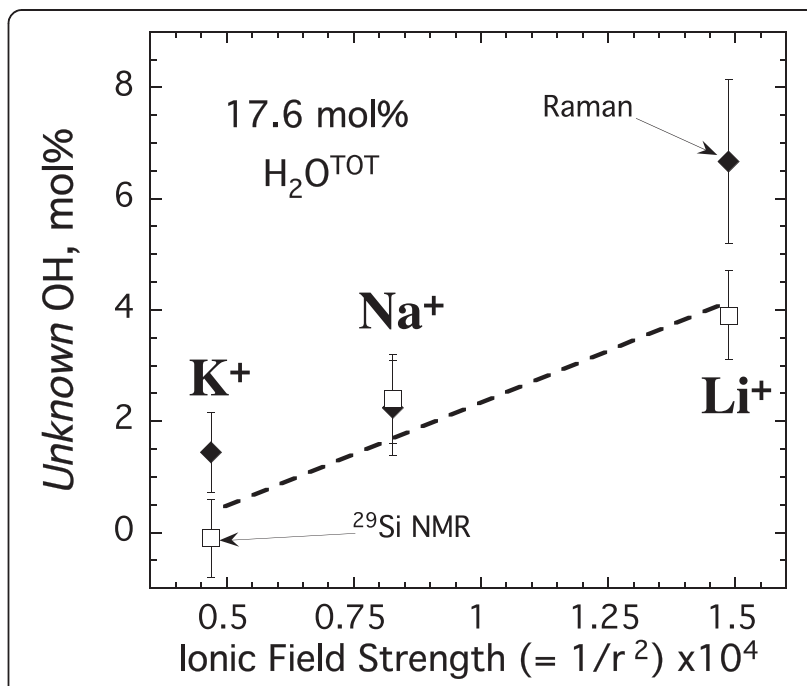

Fig. 9 Concentrations of unknown $\mathrm{OH}$ groups that do not participate in the depolymerization of the silicate network in the $17.6 \mathrm{~mol} \%$ water glasses, represented as a function of the ionic field strength (IFS) of alkali. IFS $=Z / r^{2}$ with $Z$ the electric charge and $r$ the ionic radii of the alkalis (from Whittaker and Muntus 1970 assuming sixfold oxygen-coordinated alkalis). IFS was multiplied by $10^{4}$ for clarity purpose. The black dashed line is a linear fit of the mol\% unknown $\mathrm{OH}$ vs alkali IFS relationship calculated using NMR data. Error bars are given at the $1 \sigma$ confidence interval

negligible for the KS4 glass whereas it is maximum for the LS4 glass, which also has a negligible $\triangle N B O / T$. It follows, therefore, that the chemical composition of the melt, in terms of ionic radius of the alkali metal, not only affects the speciation of water between $\mathrm{OH}$ groups and $\mathrm{H}_{2} \mathrm{O}_{\text {mol }}$ species (Fig. 7), but also affects the bonding of the $\mathrm{OH}$ groups with the quenched melt structure (Figs. 8 and 9). The effect of the water concentration is less clear. From the Raman-derived $\mathrm{SiOH}$ contents, the fraction of unknown OH groups may increase in LS4 and NS4 with addition of water, whereas it may slightly decrease in the case of the KS4 glasses (Table 4). However, those values are difficult to interpret with confidence because they have not been validated by ${ }^{29} \mathrm{Si}$ NMR spectroscopy. This validation seems necessary in regards of the errors that can affect the $\triangle N B O / T$ determined from Raman spectroscopy, as shown by the data for LS4 (see Fig. 6).

Previous studies of hydrous sodium silicate glasses indicated that, at $80 \mathrm{~mol} \% \mathrm{SiO}_{2}$, Eq. (2) appears to describe the mechanism of water solution in glasses (Zotov and Keppler 1998; Cody et al. 2005; Mysen and Cody 2005). The content of unknown $\mathrm{OH}$ is low in the NS4 glasses, near $2 \mathrm{~mol} \%$ for a nominal total water content of $17.4 \mathrm{~mol} \%$ (Table 4 and Fig. 9). The errors affecting the $Q^{n}$ fractions determined by Raman or ${ }^{29} \mathrm{Si}$ NMR spectroscopy combined 
with those affecting the determination of the concentrations of total $\mathrm{OH}$ groups render difficult the detection of such a low amount. This may explain why previous studies of sodium silicate glasses containing high silica contents did not see such small concentrations of $\mathrm{OH}$ groups not bonded to $\mathrm{Si}$. However, in alkaline-earth and alkali silicate glasses with low silica contents $(\mathrm{NBO} / \mathrm{T}>\sim 1)$, presence of $\mathrm{OH}$ groups not bonded to Si has been inferred (e.g., Xue and Kanzaki 2004; Cody et al. 2005; Mysen and Cody 2005).

Present data indicate that Eq. (2) alone cannot explain the solution mechanism of water in silicate glasses containing small alkali metals, such as $\mathrm{Li}$ and $\mathrm{Na}$. Another mechanism implying a different bonding of $\mathrm{OH}$ group must be considered. The concentration of total $\mathrm{OH}$ groups measured by IR in LS4 glasses is much higher than that of $\mathrm{OH}$ bonded to Si (Figs. 8 and 9). This indicates that the unknown $\mathrm{OH}$ groups contribute to the $4100-4500 \mathrm{~cm}^{-1}$ portion of IR spectra, where the peak assigned to the combination of the $\mathrm{OH}$ groups vibrational modes is usually observed (e.g., see Fig. 1). To our knowledge, three hypotheses can explain observations: (1) the formation of $\mathrm{MOH}$ groups, where $\mathrm{M}$ is an alkali; (2) the protonation of bridging $\mathrm{Si}-\mathrm{O}-\mathrm{Si}$ bonds; or (3) the protonation of $\mathrm{Si}-\mathrm{O}-\mathrm{M}$ bonds.

Infrared spectra of crystalline alkali hydroxide show absorption bands in the $4000-4400 \mathrm{~cm}^{-1}$ portion of IR spectra. It has been proposed that they arise from the combination of the $\mathrm{O}-\mathrm{H}$ fundamental stretching vibrations with the lattice modes (Buchanan 1959; Wickersheim 1959; Snyder et al. 1960). Therefore, contribution from $\mathrm{MOH}$ species in the $4100-4500 \mathrm{~cm}^{-1}$ range of the IR spectra of the present glasses seems possible, so that the observed unknown $\mathrm{OH}$ could be $\mathrm{MOH}$ species. In this line of thinking, we note that the IR peak near $4500-4600 \mathrm{~cm}^{-1}$ is also observed in hydrous soda-lime-borate glasses and assigned to the combination of the $\mathrm{OH}$ stretching with lattice vibrational modes (Bauer et al. 2015). Therefore, the $4500 \mathrm{~cm}^{-1}$ IR peak in hydrous glasses not only contains contributions of $\mathrm{OH}$ groups bonded to $\mathrm{Si}$, as it has been previously inferred (e.g., Malfait 2009 and references therein), but also possible contributions from other $\mathrm{OH}$ species bonded to metallic elements or even boron, as shown by the data of Bauer et al. (2015).

Hypothesis (2) involves the protonation of $\mathrm{Si}-\mathrm{O}-\mathrm{Si}$ bonds and thus the formation of $\mathrm{Si}-(\mathrm{OH})-\mathrm{Si}$ protonated bonds. A similar hypothesis has been proposed to account for water solution in glasses along the joined $\mathrm{SiO}_{2}{ }^{-}$ $\mathrm{NaAlO}_{2}$ because of the apparently negligible changes of ${ }^{29} \mathrm{Si}$ and ${ }^{27} \mathrm{Al} \mathrm{NMR}$ signals upon water addition to these glasses (Kohn et al. 1989b, 1992, 1998). Molecular orbital calculations indicate that both $\mathrm{Si}-\mathrm{OH}$ and $\mathrm{Si}-(\mathrm{OH})-\mathrm{Si}$ bonds give signals near $900 \mathrm{~cm}^{-1}$ (Kubicki and Sykes 2004), so that the $\mathrm{OH}$ groups involved in $\mathrm{Si}-(\mathrm{OH})-\mathrm{Si}$ bonds will contribute to the IR combination peak near 4500 $\mathrm{cm}^{-1}$. Therefore, the unknown $\mathrm{OH}$ groups may be involved in $\mathrm{Si}-(\mathrm{OH})-\mathrm{Si}$ bonds.

Hypothesis (3) involves the protonation of $\mathrm{Si}-\mathrm{O}-\mathrm{M}$ bonds and the formation of $\mathrm{Si}-(\mathrm{OH})-\mathrm{M}$ protonated bonds. In this hypothesis, it must be inferred that the $\mathrm{Si}-(\mathrm{OH})-\mathrm{M}$ bonds give a signal similar to that of $\mathrm{Si}-$ $(\mathrm{OH})$-Si protonated bonds near $900 \mathrm{~cm}^{-1}$, such that those bonds will contribute to the IR combination peak near $4500 \mathrm{~cm}^{-1}$.

To discriminate between those hypotheses, several points have to be considered. First, the link between the size/ionic field strength (abbreviated IFS in the following) of the alkali and the concentration of unknown OH (Fig. 9) indicates that alkalis that form short (and thus strong) M$\mathrm{O}$ bonds promote unknown $\mathrm{OH}$ groups. Considering hypothesis (3), it is unlikely that protonation of $\mathrm{Si}-\mathrm{O}-\mathrm{M}$ bonds occurs when the $\mathrm{M}-\mathrm{O}$ bond strength is high, such as for $\mathrm{Li}-\mathrm{O}$ bonds, because protonation of $\mathrm{Si}-\mathrm{O}-\mathrm{M}$ bonds may be more likely to occur for stabilizing Si-O-M bonds with low $\mathrm{M}-\mathrm{O}$ bond strengths. Considering now hypothesis (2), protonation of $\mathrm{Si}-\mathrm{O}-\mathrm{Si}$ bonds would result in the appearance of positively charged $\mathrm{Si}-(\mathrm{OH})^{+}-\mathrm{Si}$ bonds that would require charge balance by a negatively charged ion, i.e., by $\mathrm{NBO}$ oxygens or "free" oxygens $\mathrm{O}^{2-}$. Such situation would require specific structural positions for the $\mathrm{Si}$ $(\mathrm{OH})^{+}-\mathrm{Si}$ bonds and the compensating oxygens and thus seems unlikely to occur at high temperature in silicate melts that lack long- and medium-range orders. It should be noted that protonation of $\mathrm{Si}-\mathrm{O}-\mathrm{Al}$ bonds has been inferred in aluminosilicate compositions because it may help the electrical charge compensation of $\mathrm{AlO}_{2}$ tetrahedral units, but it also has been strongly questioned (see introduction of Malfait and Xue 2010 and references cited therein). Indeed, the most recent data point to formation of $\mathrm{SiOH}$ and $\mathrm{AlOH}$ groups in aluminosilicate glasses and not to protonation of bridging oxygen (e.g., see Xue and Kanzaki 2009, Malfait and Xue 2010 and references cited therein).

Therefore, the most plausible hypothesis to explain the observations of a fraction of $\mathrm{OH}$ groups not bonded to $\mathrm{Si}$ in the alkali silicate glasses is the formation of $\mathrm{MOH}$ groups. In particular, this hypothesis explains the link between the alkali IFS and the concentration of unknown $\mathrm{OH}$ groups (Fig. 9): metal cations with strong $\mathrm{M}-\mathrm{O}$ bonds may help stabilizing $\mathrm{MOH}$ complexes, in agreement with interpretations of Xue and Kanzaki (2004). In addition, this hypothesis is supported by ${ }^{1} \mathrm{H}$ MAS and ${ }^{1} \mathrm{H}->^{29} \mathrm{Si}->^{1} \mathrm{H}$ CP MAS NMR data on $\mathrm{Ca}$ and $\mathrm{Mg}$ silicate glasses that indicate the present of $\mathrm{MOH}$ groups in such compositions (Xue 2009). Therefore, from the above discussion, the unknown $\mathrm{OH}$ groups likely are bonded to alkali elements, forming $\mathrm{MOH}$ molecular complexes. 
We propose the following framework to explain the spectroscopic observations. A condition for the reaction of $\mathrm{H}_{2} \mathrm{O}_{\text {mol }}$ species with the network of silicate melts is the self-ionization of $\mathrm{H}_{2} \mathrm{O}_{\text {mol }}$ species (Moretti et al. 2014):

$$
\mathrm{H}_{2} \mathrm{O}_{\text {mol (melt) }}<=>\mathrm{H}^{+}{ }_{\text {(melt) }}+\mathrm{OH}^{-} \text {(melt) }
$$

When $\mathrm{H}_{2} \mathrm{O}_{\text {mol }}$ reacts with $\mathrm{Si}-\mathrm{O}-\mathrm{Si}$ bonds, $\mathrm{H}^{+}$and $\mathrm{OH}^{-}$ are consumed to form $\mathrm{SiOH}$ bonds, leading to the process described by Eq. (2). In the present silica-rich glasses, $\mathrm{H}^{+}$and $\mathrm{OH}$ preferentially react with $Q^{4}$ bonds to form $Q^{2}$ and $Q^{3}$ species (Fig. 5), so that the depolymerization mechanism can be described by Eq. (7), confirming previous observations in similar composition (Zotov and Keppler 1998; Cody et al. 2005; Xue and Kanzaki 2004; Mysen and Cody 2005). Decreasing the ionic radius, and hence, increasing the IFS of alkali metal in silicate melts inhibits the self-ionization reaction of water (Fig. 7) but also promotes reaction of $\mathrm{H}^{+}$and $\mathrm{OH}^{-}$with the non-bridging oxygen $\mathrm{NBO}$ and the alkalis of the Si-O-M bonds (Fig. 9) following:

$$
\mathrm{H}_{2} \mathrm{O}_{\mathrm{mol}}+\mathrm{SiOM}<=>\mathrm{SiOH}+\mathrm{MOH}
$$

Such a mechanism was proposed by Xue and Kanzaki (2004), who suggested the formation of $\mathrm{MOH}$ complexes in highly depolymerized $\mathrm{Ca}, \mathrm{Mg}$, and $\mathrm{Na}$ silicate melts $(\mathrm{NBO} / \mathrm{T}>1)$ on the basis of molecular dynamic calculations and ${ }^{1} \mathrm{H}$ MAS NMR observations. They also proposed the following reaction (see also Mysen and Cody 2005):

$$
2 \mathrm{SiOM}+\mathrm{H}_{2} \mathrm{O}_{\mathrm{mol}}<=>\mathrm{SiOSi}+2 \mathrm{MOH},
$$

Formation of $\mathrm{MOH}$ species can result in no change (Eq. (9)) or even in an increase (Eq. (10)) of the melt polymerization. Xue and Kanzaki (2004) indicated that such mechanisms mostly concerned depolymerized melts $(\mathrm{NBO} / \mathrm{T}>\sim 1)$ (see also the discussion in Xue and Kanzaki 2009), in agreement with the findings of Cody et al. (2005) and Mysen and Cody (2005). However, the water solution mechanism for the LS4 glass is best described by the combination of Eqs. (8) and (9). Therefore, the present data support the solution mechanism described with Eq. (9) in melts with relatively high silica contents $(\mathrm{NBO} / \mathrm{T} \sim 0.5)$ that contain network modifier elements with high IFS (Fig. 9).

According to the present data (Figs. 7, 8, and 9), IFS of network modifying alkali metals plays an important role in defining the equilibrium constants of Eqs. (8) (selfionization of water), (2) ( $\mathrm{SiOH}$ formation), (9) and (10) ( $\mathrm{MOH}$ formation). The origin of such role could arise from electronic/steric considerations, hydration shell formation, or volume effects around alkalis governed by their size/IFS (Le Losq et al. 2015a). For instance, electronic effects may influence the hydrolysis energy of $\mathrm{Si}-\mathrm{O}-\mathrm{Si}$ and $\mathrm{Si}-\mathrm{O}-\mathrm{M}$ bonds, and hence, the equilibrium constants of reactions (2), (9), and (10) (i.e., see discussion in Xue and Kanzaki 2004). Volume effects cannot be excluded. For instance, large alkalis may inhibit the presence of cavities in which $\mathrm{H}_{2} \mathrm{O}_{\text {mol }}$ species might be contained, and hence, will result in a large equilibrium constant for reaction (8). Formation of hydration shell around small alkalis may also help explaining the speciation of water (Fig. 7). Finally, IFS of metal cations may also affect the stability of $\mathrm{MOH}$ molecular complexes (Xue and Kanzaki 2004), explaining the link between the IFS of metal cations and the concentration of observed $\mathrm{MOH}$ groups (Fig. 9). However, the present data do not allow us to discriminate between those hypotheses. In addition, it cannot be excluded that several mechanisms play roles at the same time. Despite that, it is clear that the influence of the alkali IFS on the speciation, environment, and bonding of water in silicate quenched melts results in differences in water solubility (Mysen and Acton 1999; Mysen and Cody 2004) and partial molar volume (Mysen and Cody 2004). Beyond such concerns, the differences of bonding and speciation of water in hydrous glasses as a function of their chemical composition probably also result in variations in their physical properties such as their glass transition temperature and density.

\section{Conclusions}

The water speciation in glasses is that of the melts at their glass transition temperature, $\mathrm{Tg}$ (see for instance Nowak and Behrens 1995). Present results show that IFS of alkali affects the speciation of dissolved water between $\mathrm{H}_{2} \mathrm{O}_{\text {mol }}$ species and $\mathrm{OH}$ groups, as well as the $\mathrm{OH}$ bonding mechanisms in glasses, and hence, in melts at their $\mathrm{Tg}$. Therefore, the chemical composition of silicate melts affects the solution mechanisms of water (Figs. 7, 8, and 9), resulting in different effects on melt structures at $\mathrm{Tg}$ (Figs. 3, 4, 5, and 6). In addition, variations in the solubility of water with ionic radius of the alkali in tetrasilicate melts (see data for NS4 and KS4 in Mysen and Cody 2004) at given temperature and pressure indicate that such interplay between the melt composition, water solution mechanism, and the melt structure affects the solubility of water. As a result, such interplay probably drives the water exsolution history of magmas.

In addition to such effect, this complex interplay implies that water will affect differently the rheological properties of magmas depending on their composition. Indeed, the strong changes in melt structure (Figs. 4, 5, and 6) that accompanies variations in water solution mechanism (Figs. 7, 8, and 9) probably result in different glass transition temperatures for the hydrous alkali tetrasilicate 
glasses at given $\left[\mathrm{H}_{2} \mathrm{O}^{\mathrm{TOT}}\right]$, and, as a corollary, in different viscosity vs temperature paths. The present data do not allow us to make inferences on the extent of those differences, but they are expected to occur in view of the intimate link between the structure and the viscosity of alkali silicate melts (e.g., see Mysen and Richet 2005 for further details). Therefore, magmas with different chemical compositions will not only present different degassing paths, but also they will present different changes in their viscosity as a function of water content and temperature. Such consideration might be important for assessing about volcanic processes intimately linked to the viscous relaxation of magmas, such as the fragmentation that occurs in explosive eruptions (Papale 1999). Indeed, following the above ideas, the complex interplay between the magma composition, molecular structure, viscous properties, and the water solution mechanisms and solubility may influence the fragmentation threshold of magmas.

\section{Abbreviations}

EDS: energy-dispersive x-ray spectroscopy; SP: single pulse; MAS: magic angle spinning; NMR: nuclear magnetic resonance; IR: infrared; IFS: ionic field strength.

\section{Competing interests}

The authors declare that they have no competing interests.

\section{Authors' contributions}

BOM and GDC proposed the study. CLL made the experimental study, treated and interpreted data, and drafted the manuscript. BOM helped CLL for the experiments and lead the study. GDC performed the NMR experiments with the help of CLL. BOM and GDC collaborated with CLL in the construction of the manuscript. All authors read and approve the final manuscript.

\section{Authors' information}

CLL performed this study as a Postdoctoral Fellow at the Geophysical Laboratory, Carnegie Institution of Science, Washington DC, USA, under the mentorship of BOM and GDC, respectively Senior Scientist at, and Acting Director of the Geophysical Laboratory.

\section{Acknowledgements}

This research was partially supported by grants EAR1212754 and EAR1250449 to BOM and the NASA Astrobiology Institute. All NMR experiments were performed at the W. M. Keck Solid State NMR Facility at the Geophysical Laboratory, supported in part by the W. M. Keck Foundation, the NSF, and the Carnegie Institution of Washington.

This paper belongs to the Solid Earth Sciences section.

Received: 19 February 2015 Accepted: 2 August 2015

Published online: 14 August 2015

\section{References}

Bartholomew RF, Butler BL, Hoover HL, Wu CK (1980) Infrared spectra of a water-containing glass. J Am Ceram Soc 63:481-485

Bauer U, Behrens H, Fechtelkord M, Reinsch S, Deubener J (2015) Water- and boron speciation in hydrous soda-lime-borate glasses. J Non Cryst Solids 423-424:58-67

Behrens H, Yamashita S (2008) Water speciation in hydrous sodium tetrasilicate and hexasilicate melts: constraint from high temperature NIR spectroscopy. Chem Geol 256:306-315

Bell RJ, Bird NF, Dean P (1968) The vibrational spectra of vitreous silica, germania and beryllium fluoride. J Physics C (Proc phys soc) 1:299-303

Blake S (1984) Volatile oversaturation during the evolution of silicic magma chambers as an eruption trigger. J Geophys Res 89:8237-8244

Brawer SA, White WB (1975) Raman spectroscopic investigation of the structure of silicate glasses. I. The binary alkali silicates*. J Chem Phys 63:2421-2432
Brawer SA, White WB (1977) Raman spectroscopic investigation of the structure of silicate glasses (II). Soda-alkaline earth-alumina ternary and quaternary glasses. J Non Cryst Solids 23:261-278

Buchanan RA (1959) Near infrared spectra of crystalline alkali hydroxides. J Chem Phys 31:870-874

Clemens JD (1984) Water contents of silicic to intermediate magmas. Lithos 17:273-28

Cody GD, Mysen BO, Lee SK (2005) Structure vs. composition: a solid-state ${ }^{1} \mathrm{H}$ and ${ }^{29} \mathrm{Si}$ NMR study of quenched glasses along the $\mathrm{Na}_{2} \mathrm{O}-\mathrm{SiO}_{2}-\mathrm{H}_{2} \mathrm{O}$ join. Geochim Cosmochim Acta 69:2373-2384

Dingwell DB, Romano C, Hess KU (1996) The effect of water on the viscosity of a haplogranitic melt under P-T-X conditions relevant to silicic volcanism. Contribut Mineral Petrol 124:19-28

Eckert H, Yesinowski JP, Silver LA, Stolper EM (1988) Water in silicate glasses: quantification and structural studies by ${ }^{1} \mathrm{H}$ solid echo and MAS-NMR methods. J Phys Chem 92:2055-2064

Farnan I, Kohn SC, Dupree R (1987) A study of the structural role of water in hydrous silica glass using cross-polarisation magic angle spinning NMR. Geochim Cosmochim Acta 51:2869-2873

Friedman I, Long W, Smith RL (1963) Viscosity and water content of rhyolite glass. J Geophys Res 68:6524-6535

Furukawa T, Fox KE, White WB (1981) Raman spectroscopic investigation of the structure of silicate glasses. III. Raman intensities and structural units in sodium silicate glasses. J Chem Phys 75:3226-3237

Galeener FL (1979) Band limits and the vibrational spectra of tetrahedral glasses. Phys Rev B 19:4292-4397

Gardner JE, Thomas RME, Jaupart C, Tait S (1996) Fragmentation of magma during Plinian volcanic eruptions. Bull Volcanol 58:144-162

Kohn SC, Dupree R, Mortuza MG (1992) The interaction between water and aluminosilicate magmas. Chem Geol 96:399-409

Kohn SC, Dupree R, Smith ME (1989a) Proton environments and hydrogenbonding in hydrous silicate glasses from proton NMR. Nature 337:539-541

Kohn SC, Dupree R, Smith ME (1989b) A multinuclear magnetic resonance study of the structure of hydrous albite glass. Geochim Cosmochim Acta 53:2925-2935

Kohn SC, Smith ME, Dirken PJ, Van Eck ERH, Kentgens APM, Dupree R (1998) Sodium environment in dry and hydrous albite glasses: Improved ${ }^{23} \mathrm{Na}$ solid state NMR data and their implications for water dissolution mechanisms. Geochim Cosmochim Acta 62:79-87

Kubicki JD, Sykes DG (2004) Ab initio calculation of ${ }^{1} \mathrm{H},{ }^{17} \mathrm{O},{ }^{27} \mathrm{Al}$ and ${ }^{29} \mathrm{Si} \mathrm{NMR}$ parameters, vibrational frequencies and bonding energetics in hydrous silicate and Na-aluminosilicate glasses. Geochim Cosmochim Acta 68:3909-3918

Le Losq C, Neuville DR (2013) Effect of the $\mathrm{Na} / \mathrm{K}$ mixing on the structure and the rheology of tectosilicate silica-rich melts. Chem Geol 346:57-71

Le Losq C, Cody GD, Mysen BO (2015a) Alkali influence on the water speciation and the environment of protons in silicate glasses revealed by ${ }^{1} \mathrm{H}$ MAS NMR spectroscopy. Am Mineral 100:466-473

Le Losq C, Cody GD, Mysen BO (2015b) Complex stretching signal of OH groups in silicate glasses: implication for the use of the $4500 \mathrm{~cm}^{-1}$ IR peak as a marker of $\mathrm{OH}^{-}$groups concentration. Am Mineral 100:945-950

Le Losq C, Neuville DR, Florian P, Henderson GS, Massiot D (2014) The role of Al ${ }^{3+}$ on rheology and structural changes of sodium silicate and aluminosilicate glasses and melts. Geochim Cosmochim Acta 126:495-517

Leonteva A (1940) Measurements of the viscosity of obsidian and of hydrated glasses. Izvestiya Akademii Nauk SSSR. Ser Geol 2:44-54

Lippmaa E, Mägi M, Samoson A, Engelhardt G, Grimmer A-R (1980) Structural studies of silicates by solid-state high-resolution ${ }^{29} \mathrm{Si} \mathrm{NMR}$. J Am Chem Soc 102:4889-4893

Maekawa H, Maekawa T, Kawamura K, Yokohama T (1991) The structural groups of alkali silicate glasses determined from ${ }^{29} \mathrm{Si}$ MAS-NMR. J Non Cryst Solids 127:53-64

Malfait WJ (2009) The $4500 \mathrm{~cm}-1$ infrared absorption band in hydrous aluminosilicate glasses is a combination band of the fundamental $\{\mathrm{Si}, \mathrm{Al}\}-\mathrm{OH}$ and O-H vibrations. Am Mineral 94:849-852

Malfait WJ, Xue X (2010) The nature of hydroxyl groups in aluminosilicate glasses: Quantifying $\mathrm{Si}-\mathrm{OH}$ and $\mathrm{Al}-\mathrm{OH}$ abundances along the $\mathrm{SiO}_{2}-\mathrm{NaAlSiO}_{4}$ join by ${ }^{1} \mathrm{H}$, ${ }^{27} \mathrm{Al}-{ }^{-} \mathrm{H}$ and ${ }^{29} \mathrm{Si}^{-1} \mathrm{H}$ NMR spectroscopy. Geochim Cosmochim Acta 74:719-737

Matson DW, Sharma SK, Philpotts JA (1983) The structure of high-silica alkalisilicate glasses. A Raman spectroscopic investigation. J Non Cryst Solids 58:323-352

McMillan PF (1984) Structural studies of silicate glasses and melts-applications and limitations of Raman spectroscopy. Am Mineral 69:622-644 
McMillan PF, Poe BT, Stanton TR, Remmele RL (1993) A Raman spectroscopic study of $\mathrm{H} / \mathrm{D}$ isotopically substituted hydrous aluminosilicate glasses. Phys Chem Min 19:454-459

Moretti R, Le Losq C, Neuville DR (2014) The amphoteric behavior of water in silicate melts from the point of view of their ionic-polymeric constitution. Chem Geol 367:23-33

Moulson AJ, Roberts JP (1961) Water in silica glass. Trans Faraday Soc 57:1208-1216

Murdoch JB, Stebbins JF, Carmichael ISE (1985) High-resolution ${ }^{29}$ Si NMR study of silicate and aluminosilicate glasses: the effect of network-modifying cations. Am Mineral 70:332-343

Mysen $\mathrm{BO}$ (1990) Role of Al in depolymerized, peralkaline aluminosilicate melts in the systems $\mathrm{Li}_{2} \mathrm{O}-\mathrm{Al}_{2} \mathrm{O}_{3}-\mathrm{SiO}_{2}, \mathrm{Na}_{2} \mathrm{O}-\mathrm{Al}_{2} \mathrm{O}_{3}-\mathrm{SiO}_{2}$, and $\mathrm{K}_{2} \mathrm{O}-\mathrm{Al}_{2} \mathrm{O}_{3}-\mathrm{SiO}_{2}$. Am Mineral 75:120-134

Mysen $\mathrm{BO}$ (2007) The solution behavior of $\mathrm{H}_{2} \mathrm{O}$ in peralkaline aluminosilicate melts at high pressure with implications for properties of hydrous melts. Geochim Cosmochim Acta 71:1820-1834

Mysen $\mathrm{BO}$, Acton M (1999) Water in $\mathrm{H}_{2} \mathrm{O}$-saturated magma-fluid systems: solubility behavior in $\mathrm{K}_{2} \mathrm{O}-\mathrm{Al}_{2} \mathrm{O}_{3}-\mathrm{SiO}_{2}-\mathrm{H}_{2} \mathrm{O}$ to $2.0 \mathrm{GPa}$ and $1300{ }^{\circ} \mathrm{C}$. Geochim Cosmochim Acta 63:3799-3815

Mysen $\mathrm{BO}$, Cody $\mathrm{G}$ (2005) Solution mechanisms of $\mathrm{H}_{2} \mathrm{O}$ in depolymerized peralkaline melts. Geochim Cosmochim Acta 69:5557-5566

Mysen BO, Cody G (2004) Solubility and solution mechanism of $\mathrm{H}_{2} \mathrm{O}$ in alkali silicate melts and glasses at high pressure and temperature. Geochim Cosmochim Acta 68:5113-5126

Mysen BO, Frantz JD (1993) Structure and properties of alkali silicate melts at magmatic temperatures. Eur J Mineral 5:393-407

Mysen BO, Richet P (2005) Silicate glasses and melts - properties and structure. Developments in Geochemistry 10. Elsevier B.V, Amsterdam

Mysen BO, Finger LW, Virgo D, Seifert FA (1982) Curve-fitting of Raman spectra of silicate glasses. Am Mineral 67:686-695

Neuville, D. R. (1992) Etude des propriétés thermodynamiques et rheologiques des silicates fondus. Ph.D. Thesis of the Université Paris 7, 274.

Neuville DR (2006) Viscosity, structure and mixing in (Ca, Na) silicate melts. Chem Geol 229:28-41

Neuville DR, Mysen BO (1996) Role of aluminium in the silicate network: in situ, high-temperature study of glasses and melts on the join $\mathrm{SiO}_{2}-\mathrm{NaAlO}_{2}$. Geochim Cosmochim Acta 60:1727-1737

Neuville DR, de Ligny D, Henderson GS (2014) Advances in Raman spectroscopy applied to Earth and Material Sciences. Rev Mineral Geochem 78:509-541

Nowak M, Behrens H (1995) The speciation of water in haplogranitic glasses and melts determined by in situ near-infrared spectroscopy. Geochim Cosmochim Acta 59:3445-3450

Olivier L, Yuan X, Cormack AN, Jäger C (2001) Combined ${ }^{29}$ Si double quantum NMR and $\mathrm{MD}$ simulation studies of network connectivities of binary $\mathrm{Na}_{2} \mathrm{O} . \mathrm{SiO}_{2}$ glasses: new prospects and problems. J Non Cryst Solids 293-295:53-66

Papale P (1999) Strain-induced magma fragmentation in explosive eruptions. Nature 397:425-428

Richet P, Lejeune A-M, Holtz F, Roux J (1996) Water and the viscosity of andesite melts. Chem Geol 128:185-197

Richet P, Whittington AG, Holtz F, Behrens H, Ohlhorst S, Wilke M (2000) Water and the density of silicate glasses. Contribut Mineral Petrol 138:337-347

Saucier H (1952) Quelques expériences sur la viscosité à haute température de verres ayant la composition d'un granite. Influence de la vapeur d'eau sous pression. Bull de la Société Française de Minéralogie et de Cristallographie 75:1-45

Scholtze H (1960) Zur Frage der unterscheidung zwischen $\mathrm{H}_{2} \mathrm{O}$-Molekeln und $\mathrm{OH}$-gruppen in gläsern und mineralen. Naturwissenschaften 47:226-227

Schramm CM, de Jong BHWS, Parziale VE $(1984){ }^{29}$ Si magic angle spinning NMR study on local silicon environments in amorphous and crystalline lithium silicates. J Am Chem Soc 106:4396-4402

Seifert F, Mysen BO, Virgo D (1982) Three-dimensional network structure of quenched melts (glass) in the systems $\mathrm{SiO}_{2}-\mathrm{NaAlO}_{2}, \mathrm{SiO}_{2}-\mathrm{CaAl}_{2} \mathrm{O}_{4}$ and $\mathrm{SiO}_{2}-$ $\mathrm{MgAl}_{2} \mathrm{O}_{4}$. Am Mineral 67:696-717

Sen PN, Thorpe MF (1977) Phonons in AX 2 glasses: from molecular to band-like modes. Phys Rev B 15:4030-4038

Shaw HR (1963) Obsidian- $\mathrm{H}_{2} \mathrm{O}$ viscosities at 1000 and 2000 bars in the temperature range $700^{\circ}$ to $900{ }^{\circ} \mathrm{C}$. J Geophys Res 68:6337-6343

Snyder RG, Kumamoto J, Ibers JA (1960) Vibrational spectrum of crystalline potassium hydroxide. J Chem Phys 33:1171-1177
Sowerby JR, Keppler H (1999) Water speciation in rhyolitic melt determined by in-situ infrared spectroscopy. Am Mineral 84:1843-1849

Spiekermann G, Steel-McInnis M, Schmidt C, Jahn S (2012) Vibrational mode frequencies of silica species in $\mathrm{SiO}_{2}-\mathrm{H}_{2} \mathrm{O}$ liquids and glasses from ab initio molecular dynamics. J Chem Phys 136:154501

Stolen RH, Walrafen GE (1976) Water and its relation to broken bond defects in fused silica. J Chem Phys 64:2623-2631

Stolper A (1982) Water in silicate glasses: an infrared spectroscopic study. Contribut Mineral Petrol 81:1-17

Tarantola, A. (2005) Inverse problem theory and methods for model parameter estimation. Society of Industrial and Applied Mathematics

Thomas N, Jaupart C, Vergniolle S (1994) On the vesicularity of pumice. J Geophys Res 99:15633-15644

Tischendorf B, Ma C, Hammersten E, Venhuizen P, Peters M, Affatigato M, Feller S (1998) The density of alkali silicate glasses over wide compositional ranges. J Non Cryst Solids 239:197-202

Virgo D, Mysen BO, Kushiro I (1980) Anionic constitution of silicate melts quenched at $1 \mathrm{~atm}$ from Raman spectroscopy: implications for the structure of igneous melts. Science 208:1371-1373

Voigt U, Lammert H, Eckert H, Heuer A (2005) Cation clustering in lithium silicate glasses: quantitative description by solid-state NMR and molecular dynamics simulations. Phy Rev B 72:064207-1-11

Whittaker EJW, Muntus R (1970) lonic radii for use in geochemistry. Geochim Cosmochim Acta 34:945-956

Wickersheim KA (1959) Infrared absorption spectra of lithium hydroxide. J Chem Phys 31:863-869

Wu C-K (1980) Nature of incorporated water in hydrated silicate glasses. J Am Ceram Soc 63:453-457

Xue X (2009) Water speciation in hydrous silicate and aluminosilicate glasses: direct evidence from ${ }^{29} \mathrm{Si}^{-1} \mathrm{H}$ and ${ }^{27} \mathrm{Al}{ }^{-1} \mathrm{H}$ double-resonance NMR. Am Mineral 94:395-398

Xue X, Kanzaki M (2004) Dissolution mechanisms of water in depolymerized silicate melts: constraints from ${ }^{1} \mathrm{H}$ and ${ }^{29} \mathrm{Si} \mathrm{NMR}$ spectroscopy and $a b$ initio calculations. Geochim Cosmochim Acta 68:5027-5057

Xue X, Kanzaki M (2006) Depolymerization effect of water in aluminosilicate glasses: direct evidence from ${ }^{1} \mathrm{H}_{-}{ }^{27} \mathrm{Al}$ heteronuclear correlation NMR. Am Mineral 91:1922-1926

Xue X, Kanzaki M (2008) Structure of hydrous aluminosilicate glasses along the diopside-anorthite join: a comprehensive one- and two-dimensional ${ }^{1} \mathrm{H}$ and ${ }^{27}$ Al NMR study. Geochim Cosmochim Acta 72:2331-2348

Xue X, Kanzaki M (2009) Proton distributions and hydrogen bonding in crystalline and glassy hydrous silicates and related inorganic materials: insights from high-resolution solid-state nuclear magnetic resonance spectroscopy. J Am Ceram Soc 92:2803-2830

Yamashita S, Behrens H, Schmidt BC, Dupree R (2008) Water speciation in sodium silicate glasses based on NIR and NMR spectroscopy. Chem Geol 256:231-241

Zotov N, Keppler H (1998) The influence of water on the structure of hydrous sodium tetrasilicate glasses. Am Mineral 83:823-834

\section{Submit your manuscript to a SpringerOpen ${ }^{\circ}$ journal and benefit from:}

- Convenient online submission

Rigorous peer review

- Immediate publication on acceptance

- Open access: articles freely available online

- High visibility within the field

- Retaining the copyright to your article

Submit your next manuscript at springeropen.com 